Estimating the Value of Improved Distributed Photovoltaic Adoption Forecasts for Utility Resource Planning

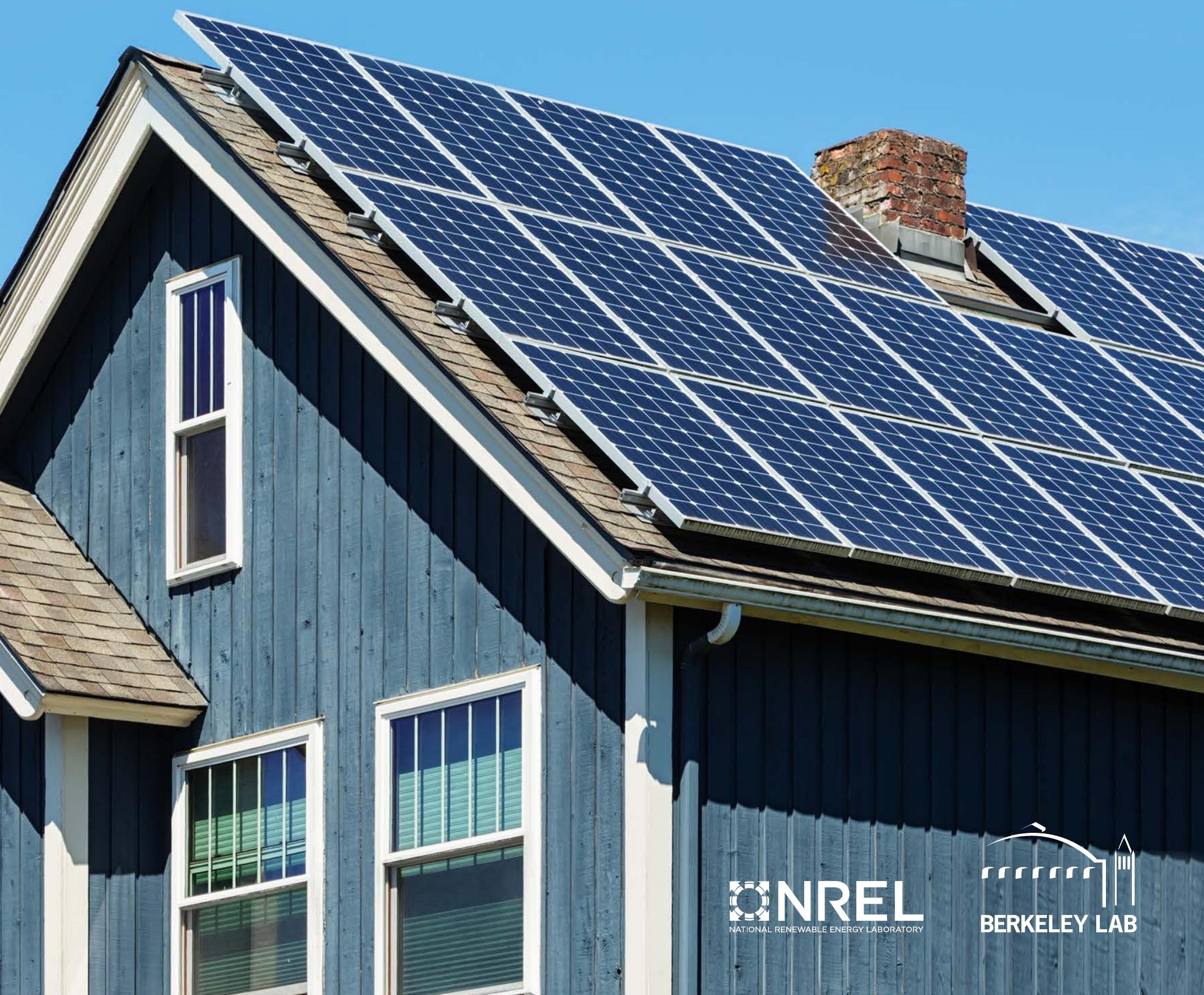




\section{Estimating the Value of Improved Distributed Photovoltaic Adoption Forecasts for Utility Resource Planning}

\author{
Pieter Gagnon, Brady Stoll, Ali Ehlen, \\ and Trieu Mai \\ National Renewable Energy Laboratory \\ Galen Barbose and Andrew Mills \\ Lawrence Berkeley National Laboratory \\ Jarrett Zuboy \\ Technical Writer
}

National Renewable Energy Laboratory 15013 Denver West Parkway Golden, CO 80401

303-275-3000 • www.nrel.gov
NREL is a national laboratory of the U.S. Department of Energy Office of Energy Efficiency \& Renewable Energy Operated by the Alliance for Sustainable Energy, LLC

This report is available at no cost from the National Renewable Energy Laboratory (NREL) at www.nrel.gov/publications.

\section{Technical Report}

NREL/TP-6A20-71042

May 2018

Contract No. DE-AC36-08GO28308 


\section{NOTICE}

This report was prepared as an account of work sponsored by an agency of the United States government. Neither the United States government nor any agency thereof, nor any of their employees, makes any warranty, express or implied, or assumes any legal liability or responsibility for the accuracy, completeness, or usefulness of any information, apparatus, product, or process disclosed, or represents that its use would not infringe privately owned rights. Reference herein to any specific commercial product, process, or service by trade name, trademark, manufacturer, or otherwise does not necessarily constitute or imply its endorsement, recommendation, or favoring by the United States government or any agency thereof. The views and opinions of authors expressed herein do not necessarily state or reflect those of the United States government or any agency thereof.

This report is available at no cost from the National Renewable Energy Laboratory (NREL) at www.nrel.gov/publications.

Available electronically at SciTech Connect http:/www.osti.gov/scitech

Available for a processing fee to U.S. Department of Energy and its contractors, in paper, from:

U.S. Department of Energy

Office of Scientific and Technical Information

P.O. Box 62

Oak Ridge, TN 37831-0062

OSTI http://www.osti.gov

Phone: 865.576.8401

Fax: 865.576.5728

Email: reports@osti.gov

Available for sale to the public, in paper, from:

U.S. Department of Commerce

National Technical Information Service

5301 Shawnee Road

Alexandria, VA 22312

NTIS http://www.ntis.gov

Phone: 800.553 .6847 or 703.605 .6000

Fax: 703.605.6900

Email: orders@ntis.gov 


\section{Suggested Citation}

Gagnon, Pieter, Galen Barbose, Brady Stoll, Ali Ehlen, Jarrett Zuboy, Trieu Mai, and Andrew Mills. 2018. Estimating the Value of Improved Distributed Photovoltaic Adoption Forecasts for Utility Resource Planning. NREL/TP-6A20-71042, Golden, CO: National Renewable Energy Laboratory; Berkeley, CA: Lawrence Berkeley National Laboratory. 


\section{ACKNOWLEDGMENTS}

This report was funded by the U.S. Department of Energy Solar Energy Technologies Office (SETO), under contract number DE-AC02-05CH11231. We thank Ammar Qusaibaty, Elaine Ulrich, Odette Mucha, and Garrett Nilsen, in particular, for their support of this work. We also thank the following individuals for reviewing and providing comments on an earlier draft of the report or for providing input as part of the project advisory group: Steven Coley (Electric Power Research Institute), Mark Dyson (Rocky Mountain Institute), James Lester (Colorado Public Utilities Commission), Carl Linvill (Regulatory Assistance Project), Richard McAllister (Western Interstate Energy Board), Zachary Ming (Energy and Environmental Economics), Chris Schroeder and John Sterling (Smart Electric Power Alliance), Tom Stanton (National Regulatory Research Institute), Chris Villareal (formerly of the Minnesota Public Utilities Commission), James Welsh (Xcel Energy), Elaine Hale (National Renewable Energy Laboratory), and Ryan Wiser (Lawrence Berkeley National Laboratory). 


\section{ACRONYMS}

CC

CSP

CT

CV

dGen

DPV

EIA

GWh

NERC

NG

NPV

NREL

O\&M

PHES

PV

REC

RPM

RPS

TES

TWh

UPV combined-cycle natural gas turbine

concentrating solar power

natural gas combustion turbine

capacity value

Distributed Generation Market Demand model

distributed photovoltaic(s)

U.S. Energy Information Administration

gigawatt-hour(s)

North American Electric Reliability Corporation

natural gas

net present value

National Renewable Energy Laboratory

operations and maintenance

pumped heat electrical storage

photovoltaic(s)

renewable energy credit

Resource Planning Model

renewable portfolio standard(s)

thermal energy storage

terawatt-hour

utility-scale PV 


\section{EXECUTIVE SUMMARY}

Many utilities have witnessed, or are anticipating, rapid growth in customer-owned distributed photovoltaics (DPV). This has prompted utilities to take a closer look at how they account for DPV growth within their resource planning processes and, in particular, their DPV adoption forecasting methods. Current resource planning practices in this area vary widely, and the state-of-the-art in DPV adoption forecasting is undergoing continuous refinement. Utility resource planners may have an interest in improving their DPV forecasting techniques. However, such improvements entail costs related to new tools, training, staffing, or contractors. Assessing whether such investments are worthwhile therefore requires some understanding — and ideally quantification—of the potential benefits associated with improved DPV adoption forecasting.

This report informs these tradeoffs by estimating how improved DPV adoption forecasts used in utility resource plans can reduce future utility capital and operating costs. We simulate future capital and operating costs for the entire Western Interconnection under varying assumptions about the accuracy of the DPV forecasts used to develop generation-expansion plans. We then describe a simplified probabilistic method that individual utilities could implement for their own service territories to estimate the potential benefits from improving their DPV forecasting capabilities. To be clear, this analysis exclusively considers the bulk power system. Depending on their locational precision, improved DPV forecasts could also benefit distribution system planning, but those impacts are outside the scope of this work.

The analysis relies on a staged series of models: the National Renewable Energy Laboratory's (NREL's) Distributed Generation Market Demand model (dGen) to project DPV adoption over time; NREL's Resource Planning Model (RPM), a capacity-expansion model, to simulate the least-cost buildout of the bulk power system; and PLEXOS, a commercial production cost model developed by Energy Exemplar, to simulate operation of the bulk power system. Using this suite of models, we estimate the present value of capital and operating costs for the Western Interconnection over a 15-year analysis period (2016-2030) across a wide range of scenarios encompassing varying levels of DPV growth and misforecasting. The 15-year analysis period comprises a series of 5-year planning increments, within each of which a new capacity-expansion plan is developed and implemented based on an erroneous DPV forecast. The presentvalue capital and operating costs under these plans are then compared to the costs under a scenario with perfect DPV forecasting, to quantify the cost of the forecasting error.

Based on this analysis, several key findings and themes emerge:

The utility-cost impacts of misforecasting DPV adoption can be non-trivial. Within our base-case analysis, systematically misforecasting DPV adoption over multiple successive planning cycles increases the present value of utility system costs by up to $\$ 7$ million per terawatt-hour (TWh) of electricity sales, relative to utility system costs under a perfect forecast (the upper left-hand corner of Figure ES-1). ${ }^{1}$ Thus, for a relatively large utility with $10 \mathrm{TWh} /$ year of sales, this translates to a $\$ 70$ million present-value cost. This cost estimate is for a relatively extreme scenario-in which the contribution of DPV within the total generation portfolio increases by $8.5 \%$ over a 15 -year period, but the utility does not assume any incremental DPV growth in each of three successive 5-year expansion plans. Naturally, the cost impacts are less acute in cases with less DPV growth or a smaller degree of misforecasting. For example, for a

\footnotetext{
${ }^{1}$ Throughout this report, we frequently refer to total costs over the 15-year study period by discounting them into present-value dollars and normalizing them by the quantity of electricity sold in the Western Interconnection in 2015. We express this as millions of 2017 dollars per TWh of electricity sales. Critically, this should not be confused with the more common metrics of $\$ / \mathrm{MWh}$ or $\$ / \mathrm{kWh}$, which are the costs at a single point in time, not the discounted sum of 15 years' worth of costs.
} 
utility with DPV growth equal to just $2 \%$ of total energy generation over 15 years or a forecasting error of just $\pm 25 \%$, the cost of misforecasting is less than $\$ 1$ million per TWh of electricity sales.

These misforecasting costs, even under the most extreme conditions, are small relative to any utility's overall cost of service. However, from the perspective of a utility resource planner, the relevant metric to consider would be the relative costs and benefits on any investment or contract, not just the absolute benefits. The results in this report suggest DPV forecasting improvements are likely to be profitable in some cases (e.g., if large DPV growth is expected but would otherwise not be incorporated in resource planning) but not others (e.g., if DPV growth is expected to be minimal). A utility can use the estimates of benefits given in this report, and their own estimates of the costs of improvements, to determine where they fall on that spectrum.

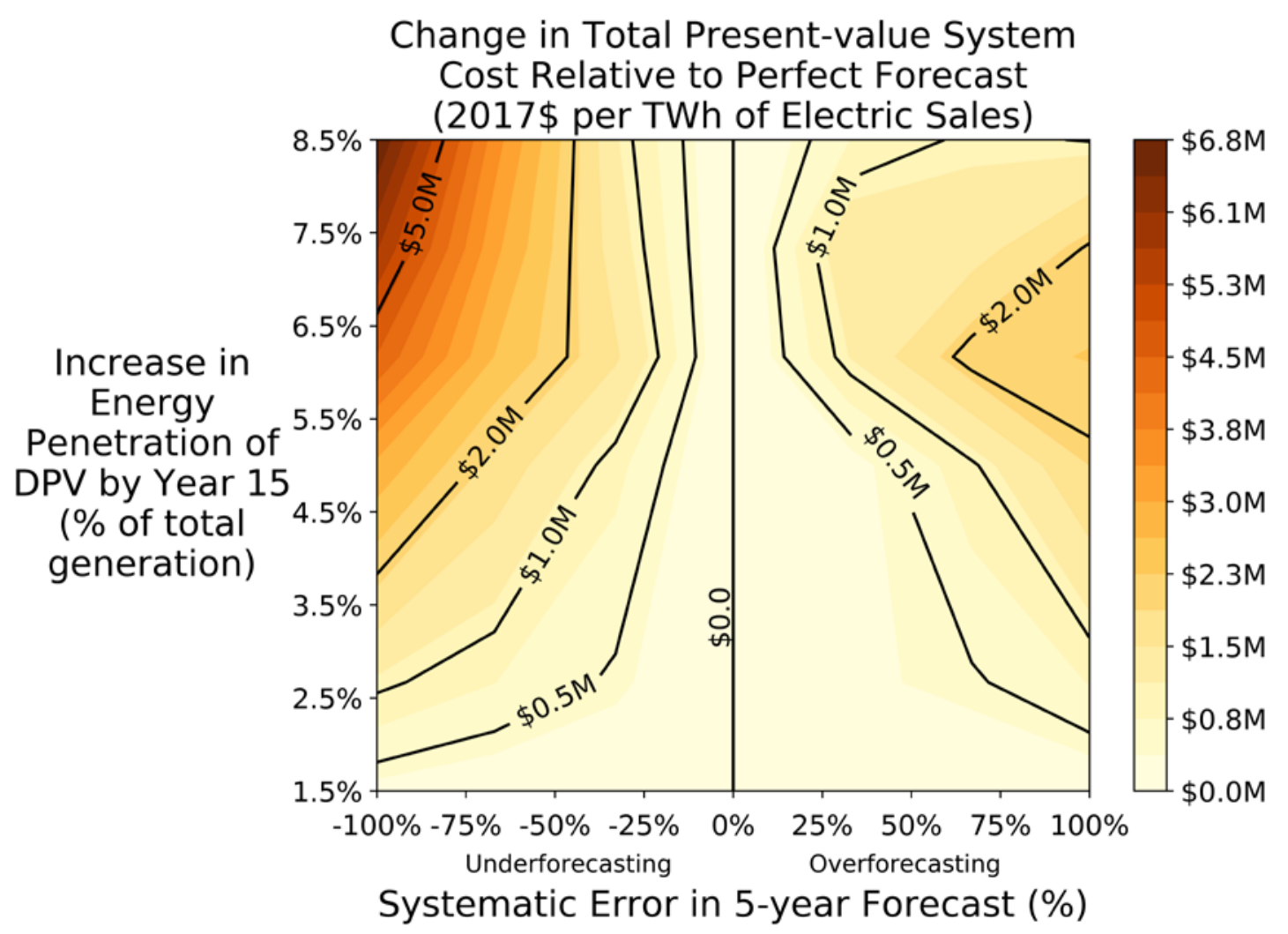

Figure ES-1. Normalized total present-value costs due to systematic DPV misforecasts in the Western Interconnection over a 15-year period

The cost of misforecasting can be asymmetrical. The cost impact cited above (\$7 million per TWh of retail sales) corresponds to a scenario with severe underforecasting of future DPV generation. In contrast, the costliest overforecasting increases utility system costs by just $\$ 2$ million per TWh within our basecase analysis (i.e., 100\% overforecasting at 6.5\% DPV increase in Figure ES-1). These particular results are specific to the system modeled in this analysis. In general, underforecasting DPV tends to increase capital costs but decrease operating costs (relative to a perfect forecast), while overforecasting DPV does the opposite. Accordingly, the magnitude and direction of any asymmetry depends on the relative degree of sensitivity of capital and operating costs to DPV forecast error. This phenomenon can have practical implications for utility resource planners, because the expected direction and magnitude of asymmetry can influence what amount of DPV in a resource plan minimizes the expected costs of misforecasting. 
The cost of misforecasting is sensitive to market and planning conditions. The Western Interconnection, as modeled in this analysis, is oversupplied with capacity in the initial years of the planning period. This partially explains the asymmetry noted above, because an initially overbuilt system may not require new capacity additions for the initial years of a planning period, and thus overforecasting DPV adoption (i.e., underforecasting load growth) has a muted impact on capacity-expansion decisions. As another example of how specific utility system conditions may impact the cost of misforecasting DPV adoption, our analysis also highlights the importance of renewable energy credit (REC) prices if a utility includes anticipated DPV RECs in its renewable portfolio standard (RPS) compliance planning. In a sensitivity case with roughly a \$20/MWh increase in REC prices (the "High REC Price" case in Figure ES-2), the cost of severely overforecasting DPV in the high-DPV case rises from $\$ 1$ million per TWh of retail sales in the base case to roughly $\$ 8$ million. This is due to the additional cost of having to purchase RECs to cover RPS compliance shortfalls. Conversely, the cost of severely underforecasting DPV falls from \$7 million per TWh to $\$ 2$ million, due to the additional revenues from the sale of surplus RECs. Features and findings from the other sensitivity cases depicted in Figure ES-2 are discussed further in the main body of this report.

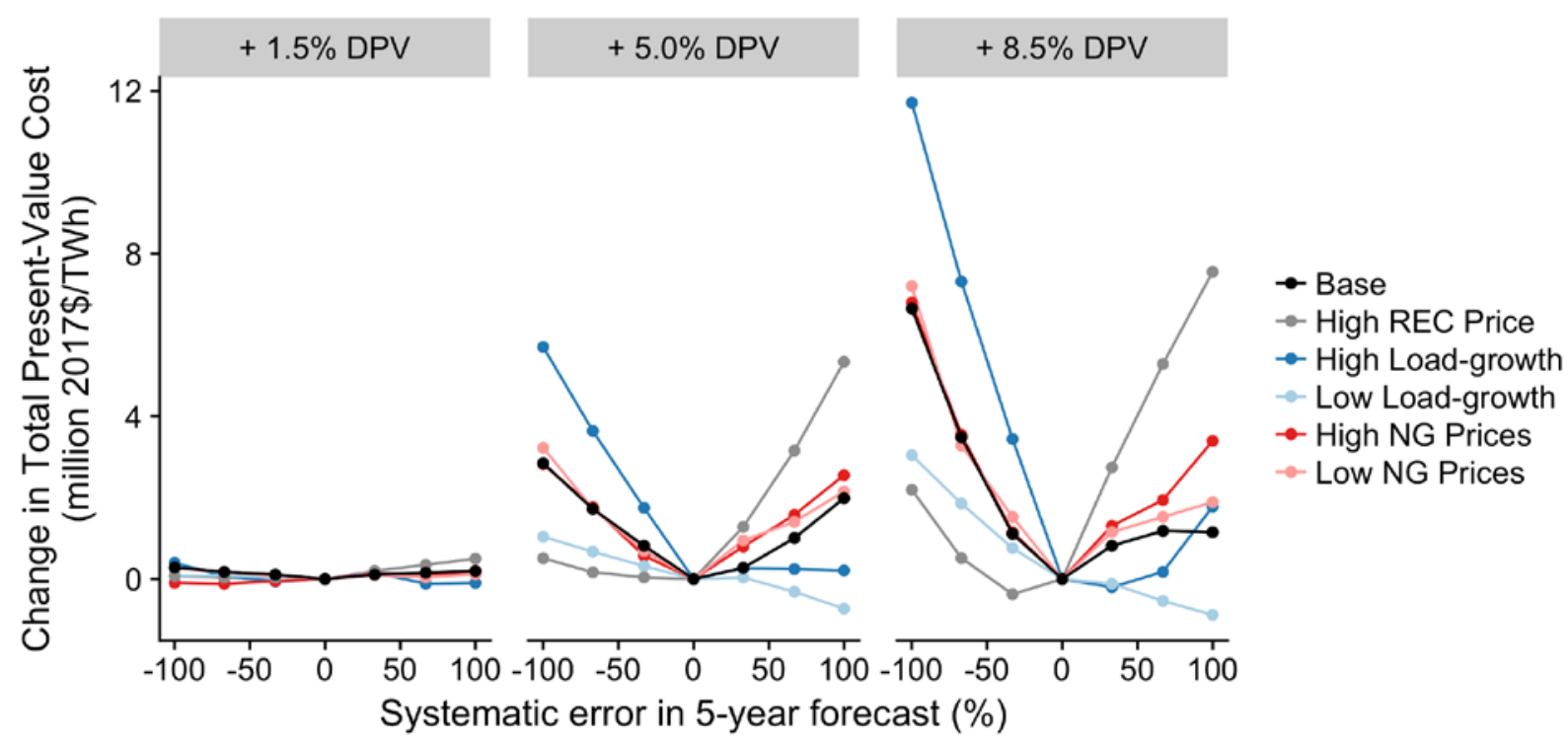

Figure ES-2. Sensitivity of change in total present-value system costs (relative to perfect forecast) to load growth rates, natural gas (NG) prices, and REC prices

Some level of uncertainty in DPV adoption forecasts is inevitable, partly owing to policy and market drivers (e.g., future PV cost trajectories, future changes to net metering rules, etc.) that are inherently uncertain. However, uncertainty in DPV adoption forecasts also partly derives from methodological shortfalls-i.e., oversimplifications or misrepresentations of the dynamics underlying customer adoption. It is that source of uncertainty that utility resource planners can potentially address through improved DPV forecasting techniques.

A utility interested in evaluating the potential benefits from improving its DPV adoption forecasting methods must therefore compare the expected costs of DPV misforecasting under its current approach against the expected costs under an improved approach with reduced uncertainty. As mentioned above, we use the modeled costs of DPV misforecasting to present a simplified probabilistic method enabling estimation of the cost savings due to reducing DPV forecast uncertainty under specific utility conditions. In the example illustrated in Figure ES-3, a large utility with $10 \mathrm{TWh} /$ year of retail sales that is planning for DPV growth of 3.5\% of total generation over 15 years would expect present-value savings of $\$ 4.0$ million by reducing its DPV forecast uncertainty from roughly $+75 \% /-55 \%$ to $\pm 25 \%$. These benefits 
would, naturally, be larger for a utility with more-significant DPV growth and/or for improvements in DPV adoption forecasting methods that yield a larger reduction in forecast uncertainty.

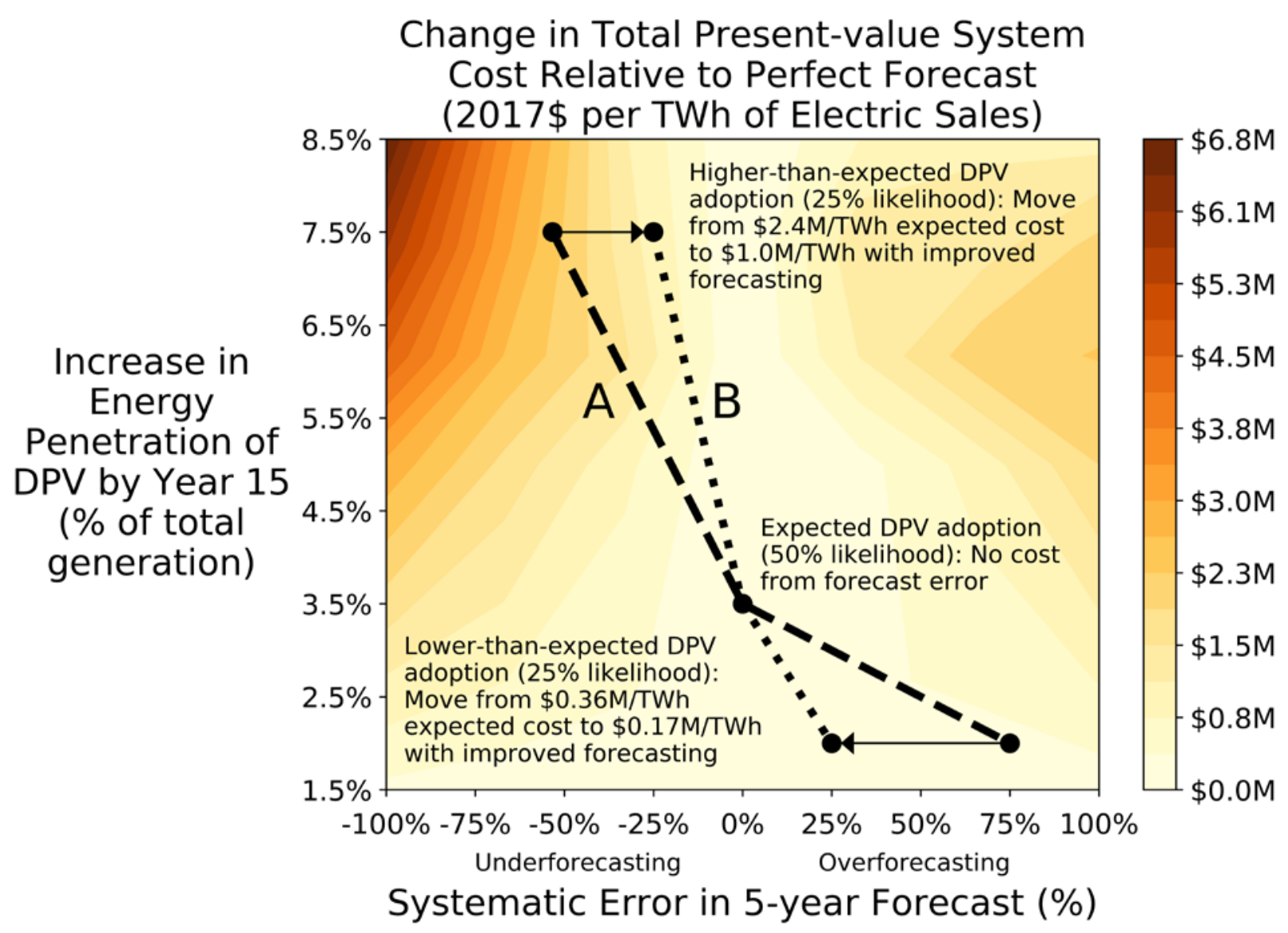

Figure ES-3. Illustration of cost savings from improving DPV forecasts

The quantitative estimates developed in this report are based on a specific electric system and period, and they rely on a host of assumptions about market and policy conditions during that period. Using these assumptions and our simplified probabilistic method, analysts can make first-order estimates of the potential cost savings from improved DPV forecasts. For any number of reasons-some of which are discussed above - the cost savings for any given utility may be higher or lower than the estimates provided here. Thus, any first-order estimates derived from the analysis in this report are most useful if followed by a robust examination of how any individual utility's circumstances deviate from the environment assumed in our modeling. That said, we hope the estimates obtainable from this report will offer a useful starting point for planners seeking to evaluate the merits of investing in improved DPV forecasting methods. 


\section{TABLE OF CONTENTS}

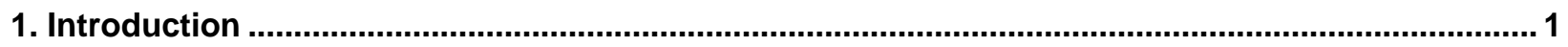

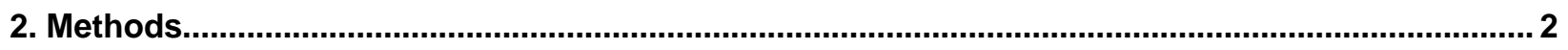

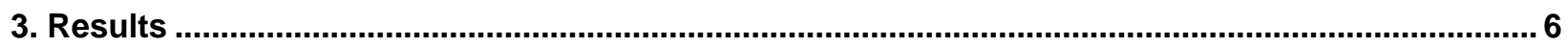

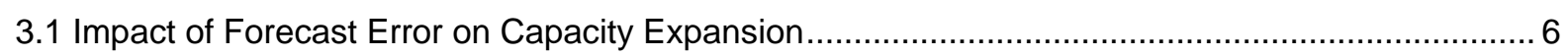

3.2 Impact of Forecast Error on Capital and Operating Costs ...................................................... 8

3.3 Normalized Impact of DPV Forecast Error on Total Costs and Value of Improved DPV Adoption

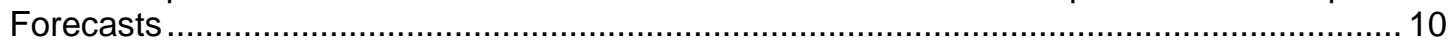

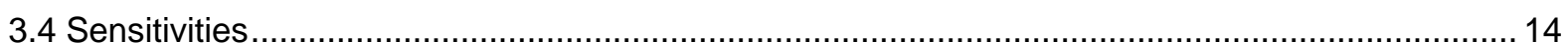

4. Conclusions

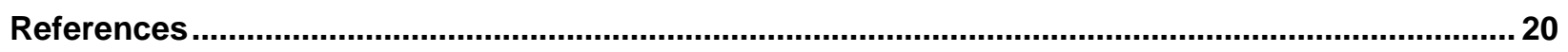

Appendix A: Detail on Capacity Differences Caused by Misforecasting ........................................ 22

Appendix B: Detailed Methodology for Estimating Value of Improved Forecasting ......................... 23

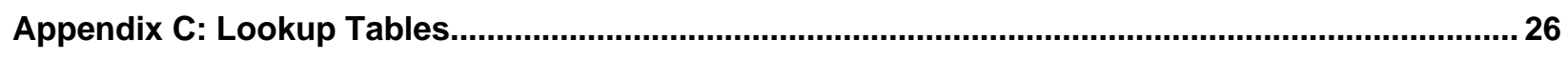

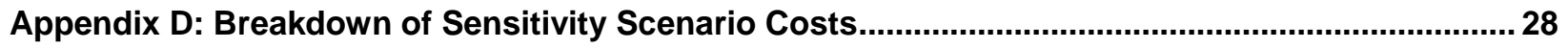




\section{LIST OF FIGURES}

Figure ES-1. Normalized total present-value costs due to systematic DPV misforecasts in the Western Interconnection over a 15-year period

Figure ES-2. Sensitivity of change in total present-value system costs (relative to perfect forecast) to load growth rates, natural gas (NG) prices, and REC prices......................................................... viii

Figure ES-3. Illustration of cost savings from improving DPV forecasts ..............................................ix

Figure 1. Systematic misforecasting, with plan updates every 5 years ......................................... 2

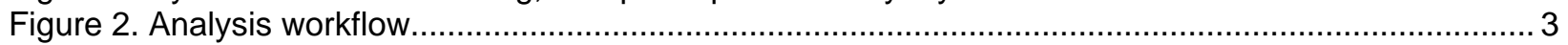

Figure 3. Example scenarios showing a range of DPV forecast error severity ...................................... 4

Figure 4. Influence of forecast error on cumulative capacity for the scenario with DPV growth over 15 years equal to $5 \%$ of total generation .................................................................................. 7

Figure 5. Difference between each technology's cumulative capacities under a range of DPV forecast errors and their cumulative capacity under perfect forecast, for the scenario with DPV growth over 15 years equal to $5 \%$ of total generation

Figure 6. Impact of forecast error on the net present value (NPV) of capital and operating costs through year 15, prior to reserve margin or RPS adjustments.

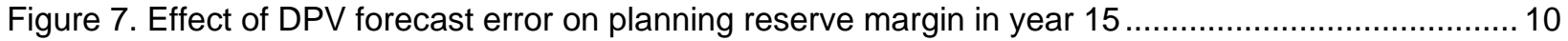

Figure 8. Impact of reliability and RPS adjustments on the NPV of capital and operating costs through year 15 (figure scales are different for capital and operating costs) ......................................... 10

Figure 9. Normalized total present-value costs due to systematic DPV misforecasts in the Western Interconnection through year 15

Figure 10. Illustration of cost savings from improving DPV forecasts ............................................. 13

Figure 11. Impact of including improved DPV forecasts into the resource planning process, relative to

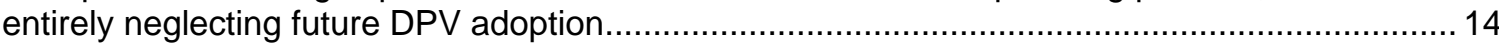

Figure 12. Sensitivity of change in total present-value system costs (relative to perfect forecast) to load growth rates, natural gas (NG) prices, and REC prices......................................................... 15

Figure 13. Natural gas price assumptions ............................................................................... 16

Figure 14. Difference in 2030 system capacity (left) and system cost NPV (right) caused by omitting the $\mathrm{CV}$ of DPV during capacity-expansion planning, values are for the entire Western Interconnection

Figure A-1. Influence of forecast error on capacity additions for three DPV penetration scenarios, relative

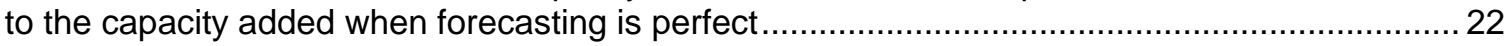

Figure B-1. Illustration of cost savings from improving DPV forecasts .............................................. 25

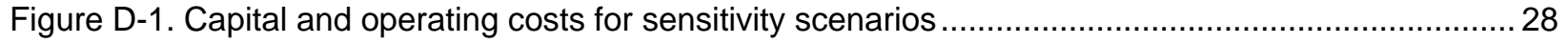

\section{LIST OF TABLES}

Table C-1. Present-value Costs of Underforecasting (2017\$ million per TWh of electric sales)............... 26

Table C-2. Present-value Costs of Overforecasting (2017\$ million per TWh of electric sales)................. 27 


\section{INTRODUCTION}

Many utilities have witnessed, or are anticipating, rapid growth in customer-owned distributed photovoltaics (DPV), prompting questions about how to best account for this emerging trend within utility resource planning processes. Mills et al. (2016) identify key issues for resource planners to consider, focusing on nine specific methodological areas. Chief among these nine areas is DPV adoption forecasting. Within the context of utility resource planning, DPV adoption forecasts are incorporated into load forecasts with the effect of reducing the forecasted load. The adjusted load forecast then forms the basis for identifying future utility resource needs and selecting a preferred set of resources to acquire over the planning horizon. Assumptions about future DPV growth can therefore have significant impacts on the quantity and type of resources that utilities procure as well as the resulting operation of the utility system.

As Mills et al. (2016) show, DPV adoption forecasting approaches currently used in utility resource plans vary widely. Although many rely on simple stipulated forecasts or extrapolations of historical trends, the most advanced utility resource plans use customer adoption models to forecast DPV growth. These models simulate customer adoption of end-use technologies based on technical potential, customer investment economics, and other behavioral considerations. Such models have been used widely for policy analysis and to forecast solar market growth (BNEF 2016, EIA 2017a, Gagnon and Sigrin 2016), and they are undergoing continuous refinement-for example, by improving underlying technical potential estimates (Gagnon et al. 2016), incorporating agent-based modeling techniques (Rai and Robinson 2015, Zhang et al. 2015), and accommodating third-party ownership (Dong and Sigrin 2016).

Improving DPV adoption forecasts in utility resource plans incurs costs, however. The improvements may require investing in new software tools, collecting data, training existing staff, or hiring new staff or consultants. Utility planners must weigh the costs of such investments against the potential benefits. This study informs those tradeoffs by estimating the potential monetary benefits of improved DPV forecasts.

To do so, we simulate future capital and operating costs for the entire Western Interconnection under varying assumptions about the accuracy of the DPV forecasts used to develop generation-expansion plans. The results show how misforecasting the amount of DPV growth can impact future electric system costs, thus illustrating the potential cost savings that may result from improved DPV forecasts. The objective is both to demonstrate a methodology that individual utilities could implement for their own service territories and to provide a set of quantitative estimates that can be scaled to approximate the potential benefits for utilities of varying sizes. The focus of this study is on the bulk power system and thus is most relevant to generation and transmission planning processes; improving DPV forecasts may also yield benefits for distribution system planning, but those impacts are outside the scope of our analysis.

The remainder of this report is organized as follows. Section 2 describes our methods. Section 3 presents the results of the analysis, including a limited set of sensitivity cases, and illustrates how these results might be used by a utility that is considering an investment in improved DPV forecasting capabilities. Finally, Section 4 provides conclusions. 


\section{Methods}

We characterize the cost of misforecasting DPV adoption by comparing electric system capital and operating costs under scenarios in which a utility consistently misforecasts DPV adoption to a scenario in which it perfectly forecasts adoption. However, given that utilities update their resource plans periodically, we also assume that the utility corrects its plan for actual historical adoption levels with each successive plan. This dynamic is illustrated in Figure 1. In this example, the utility misforecasts DPV growth by $-50 \%$ in each resource plan - that is, the forecasts of how much new DPV will be adopted (the green lines) are $50 \%$ below what actually occurs (the increase in the blue line over the same time span). As described further below, we consider a range of forecast errors-both positive and negative-each applied to a range of actual DPV adoption trajectories.

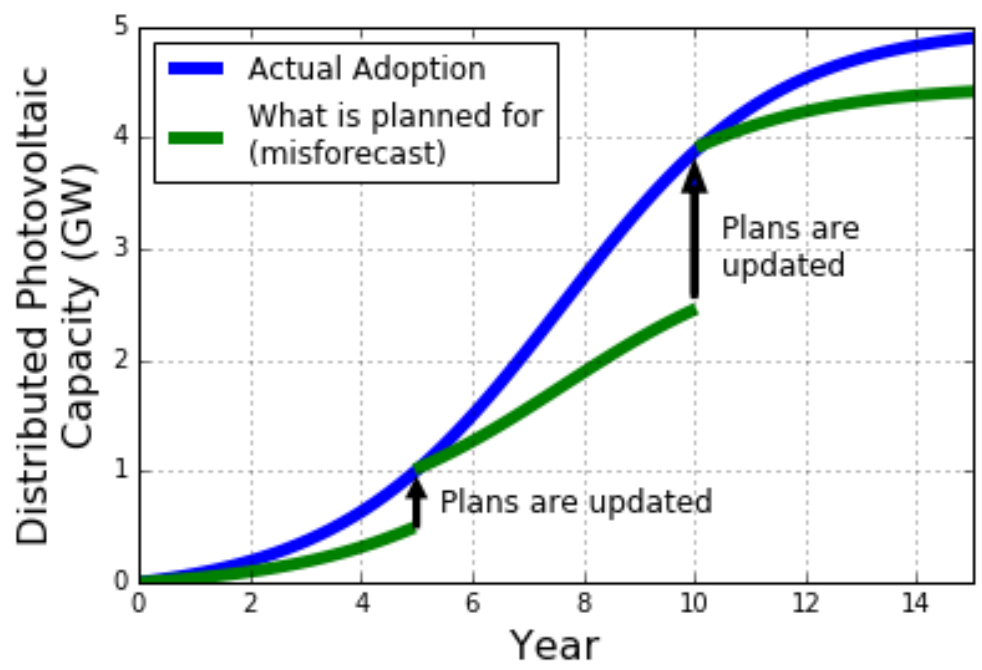

Figure 1. Systematic misforecasting, with plan updates every 5 years

The study region for our analysis is the U.S. Western Interconnection. In each scenario, all utilities in the interconnection misforecast DPV adoption by the same percentage amount, and we estimate the resulting impact on capital and operating costs across the entire interconnection. Using such a large region enables us to report "average" results that are more broadly representative than what would be produced from analyses focused on individual utilities or smaller regions. However, we also present the estimated cost of misforecasting in terms of dollars per unit of electricity sales, to show how these regional average costs may scale to an individual utility service territory.

To explore the impacts DPV misforecasting has on the costs of building and operating the Western Interconnection power system, we employ three models:

- The Distributed Generation Market Demand model (dGen), the National Renewable Energy Laboratory's (NREL's) customer adoption model, which projects patterns of DPV adoption over time (Sigrin et al. 2016).

- The Resource Planning Model (RPM), NREL's capacity-expansion model, which projects the optimal (least-cost) buildout of the bulk power system, given assumptions about future conditions as well as operational and policy constraints, such as operating reserves and renewable portfolio standards (RPS) (Hale et al. 2016). 
- PLEXOS, a commercial production cost model developed by Energy Exemplar, which we use to simulate the operation of the bulk power system given a capacity mix developed using RPM and the underlying system model developed during previous modeling efforts (Lew et al. 2013).

Using this suite of models, we estimate the present value of capital and operating costs for the Western Interconnection over a 15-year period (2016-2030), across a wide range of scenarios encompassing varying levels of DPV penetration and misforecasting. ${ }^{2}$ Figure 2 illustrates the steps in this analysis structure.

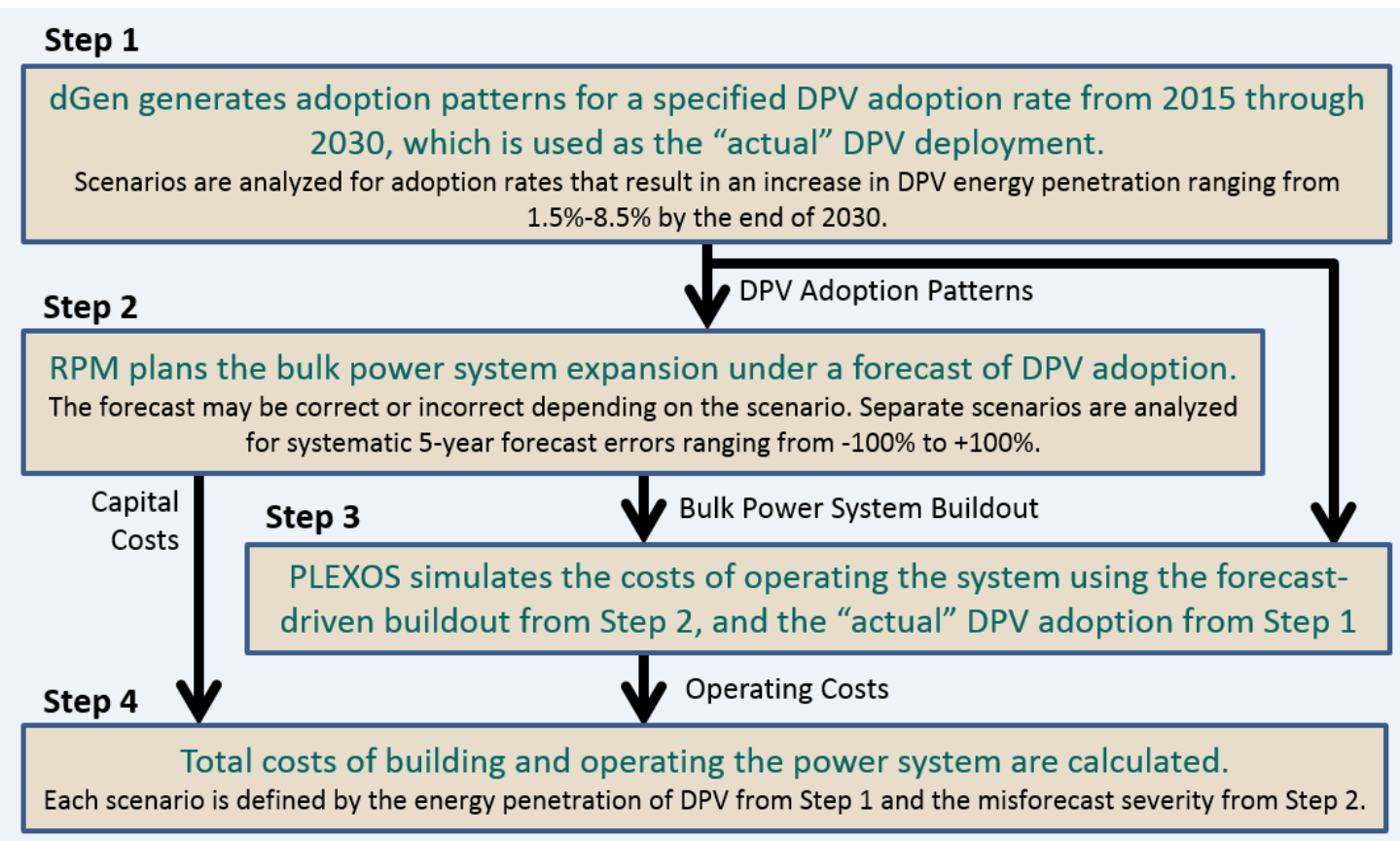

\section{Figure 2. Analysis workflow}

In Step 1, we use dGen to project DPV adoption on a county-by-county basis for a specified DPV penetration scenario from 2015 through 2030 in the Western Interconnection. For each scenario, this value becomes the "actual" DPV adoption, corresponding to the blue line in Figure 1. The real predictive accuracy of this value is unimportant; it serves merely as the nominally correct baseline adoption against which various forecasted adoptions are compared. Because the amount of DPV adopted strongly influences the cost of forecast error, we analyze separate scenarios in which DPV penetration increases from a starting value of $1.5 \%$ in 2015 to ending values of 3\%-10\% in 2030 (in terms of the percentage of total electric generation that comes from DPV).

In Step 2, we use RPM to model changes in the bulk power system. RPM chooses how much of each generating technology is built over each 5-year planning period, using a least-cost optimization framework that represents operational and policy constraints. ${ }^{3}$ The model is conceptually similar to other

\footnotetext{
2 The 15-year analysis period used in this study is intended to show how the cost impacts from misforecasting DPV adoption accumulate over multiple planning cycles. It is not necessarily meant to represent a utility resource planning horizon (which is often 20 years or more).

${ }^{3}$ We use a 5-year time-step because RPM operates in 5-year intervals. This is somewhat longer than the typical interval at which utilities update their resource plans (often every 2-3 years). However, procurement decisions resulting from resource plans often take several years to fully execute; thus, 5 years is likely a reasonable proxy for the period between the beginning of a planning cycle and the completion of all resulting capacity additions.
} 
capacity-expansion models used in utility resource planning processes, which first forecast future resource needs over some planning horizon, based on load growth and the existing resource base, and then select a least-cost mix of new resources to meet forecasted incremental needs. For each planning period, RPM assumes a certain amount of DPV when forecasting incremental needs. When the analysis is performed under an incorrect DPV forecast, corresponding to the green lines in Figure 1, RPM optimizes for a DPV penetration that does not actually occur, resulting in a sub-optimal system buildout over the following 5 years.

For each of the DPV penetration trajectories described in Step 1, we analyze scenarios with systematic 5year DPV forecast errors that range from $-100 \%$ to $+100 \%$ (i.e., ranging from a forecast of zero DPV growth to one with twice the actual level of growth), as well as a scenario in which RPM assumes the correct forecast. Figure 3 shows an example set of scenarios. The central black line represents actual DPV adoption, as described in Step 1, and each curve branching off the central line is an incorrect forecast. ${ }^{4}$ Figure 3 shows only a single DPV-penetration scenario-a similar set of curves is generated for each level of DPV penetration.

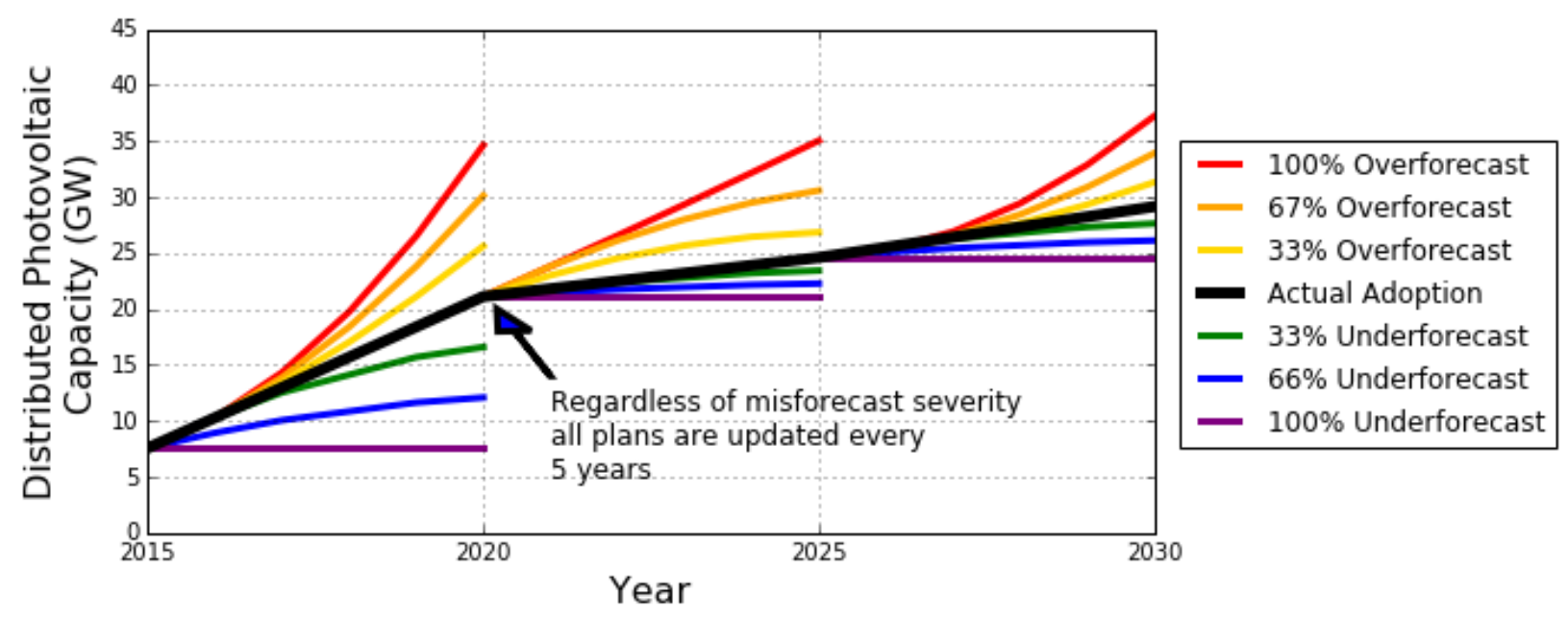

Figure 3. Example scenarios showing a range of DPV forecast error severity

In Step 3, the DPV adoption from Step 1 and the bulk power system built in Step 2 become inputs to the PLEXOS model, which simulates the cost of operating the system under these conditions. The actual amount of DPV adopted is always used in this cost modeling, because system dispatch would be based on the actual net load, and misforecasting within the planning process does not impact operational unit commitment and economic dispatch decisions. However, if the power system was built using an incorrect DPV forecast, PLEXOS outputs the cost of operating a system that was designed for a different amount of DPV adoption than actually occurred.

In Step 4, we add the capital costs calculated in RPM and the operational costs calculated in PLEXOS to arrive at the total cost of building and operating the power system. Additionally, we make adjustments to represent costs that may be incurred when procuring resources to make up for deviations to either resource adequacy or RPS requirements. In general, overforecasting can result in the planning reserve margin and/or RPS requirements not being met, since there is less capacity on the system than RPM

\footnotetext{
${ }^{4}$ In RPM, once a 5-year plan forecasts DPV at a certain level, future forecasts cannot drop below that level, even if they otherwise would based on our systematic error calculation. This modeling artifact results in asymmetries in the severity of misforecasting (e.g., compare the distance away from the actual adoption line of the $100 \%$ overforecast line vs. the 100\% underforecast line in the 2020-2025 period in Figure 3), but it does not significantly impact the results of this work.
} 
nominally anticipated. Conversely, underforecasting DPV can result in reserve margin and/or RPS requirements being exceeded.

To capture the cost impact of compensating for an unanticipated reserve margin shortfall, we add the annualized cost of an amount of natural gas combustion turbine (CT) capacity equivalent to any shortfall. This represents a utility procuring additional resources on the fly, when necessary. We do not adjust the costs for misforecast trajectories with reserve margins higher than required; in those scenarios, we assume additional capacity would have already been built before the DPV misforecast was realized. ${ }^{5}$

We apply costs to the RPS-related effects of misforecasting by adding or subtracting costs to represent the buying or selling of renewable energy credits (RECs) for any deviation from the required amount of RECs. We assume REC values equal to the median REC prices observed across all years in all of our scenarios, which range from $\$ 1 / \mathrm{MWh}$ to $\$ 3 / \mathrm{MWh}$ depending on the year. ${ }^{6}$ These low prices are driven by favorable technology assumptions, omission of administrative costs for trading, simplified restrictions on trading, liberal qualification representations, and a system-wide optimization approach that does not capture strategies such as REC banking (Barbose 2017). ${ }^{7}$ As noted below, we also consider sensitivity cases with higher REC prices.

This aggregation of capital costs, operating costs, and adjustments is performed in 5-year increments through 2030, and the values for intervening years are interpolated to estimate the total annual costs over the 15-year timeframe. This annual cash flow is discounted to a single present value, which allows us to compare the costs of building and operating the system under various actual DPV penetrations and forecast accuracies. Throughout the report we use a real discount rate of $5.4 \%$ to report the annual expenditures over the 15-year analysis period in terms of their total cost in present-value terms. ${ }^{8}$

Except where otherwise noted, our analysis follows the assumptions used in the central scenario of NREL's 2016 Standard Scenarios (Cole et al. 2016b), which draws from NREL's 2016 Annual Technology Baseline (Cole et al. 2016a) and the U.S. Energy Information Administration's (EIA's) 2016 Annual Energy Outlook (EIA 2016) for exogenous inputs such as technology and fuel prices. In Section 3.4, we examine how sensitive the results are to variations in assumed load growth, natural gas prices, and REC prices.

\footnotetext{
${ }^{5}$ In some situations, a utility would be able to sell excess capacity through short-term markets, thus generating some additional revenues to offset the costs from underforecasting; however, due to the difficulty of predicting revenues from these markets in future years under the unique scenarios we are modeling, we neglect this opportunity here. ${ }^{6}$ These are the marginal values on the RPS constraints in RPM, and they are averages for the entire Western Interconnection.

${ }^{7}$ We acknowledge that this is somewhat of an abstraction from how REC markets tend to function in the Western Interconnection. Unlike in many eastern U.S. states, where RPS compliance is achieved by purchasing tradeable, unbundled RECs, RPS compliance in most western states occurs through long-term bundled power-purchase agreements and utility-owned assets. REC markets in the western U.S. are thus relatively illiquid and tend to be highly state-specific, given state-specific RPS eligibility rules. When applying these results to a smaller region, it would be prudent to add an adjustment based on better information for the region under consideration.

${ }^{8}$ This discount rate is from NREL's Annual Technology Baseline (Cole et al. 2016a) and is an estimate of the historic long-term weighted average cost of capital for the U.S. electric sector.
} 


\section{Results}

We present our results in four sections. Section 3.1 characterizes the impact of DPV forecast error on generation capacity expansion. Section 3.2 presents the corresponding impacts on capital costs and operating costs. Section 3.3 presents our core results - the total costs from misforecasting, in presentvalue terms, including adjustments to capture reserve margin and RPS requirements. Finally, Section 3.4 analyzes the sensitivity of our results to key underlying assumptions.

Again, all the results presented here are for systematic forecast errors across the entire Western Interconnection. We initially present results in absolute dollar terms for the interconnection as a whole, but in Section 3.3 we also normalize the results on a per-terawatt-hour (TWh) basis to facilitate application to smaller regions, such as a single utility service territory. Those normalized values are intended to help utility planners develop a first-order estimate of the potential value of improved DPV adoption forecasting for their planning region.

Lastly, when describing results, we refer to both the year and DPV penetration in terms of their relative changes to starting conditions (years since 2015 and increase in DPV from 1.5\% energy penetration, respectively), since the results are more sensitive to relative changes in those variables than their absolute values.

\subsection{IMPACT OF FORECAST ERROR ON CAPACITY EXPANSION}

Here we analyze the influence of DPV forecast error on the types and amounts of generation capacity added to the bulk power system. Our analysis shows a strong relationship between the amount of DPV forecasted and the amount of utility-scale PV (UPV) that gets built. All else being equal, each forecasted gigawatt-hour (GWh) of DPV generation generally corresponds to roughly a GWh reduction in generation from UPV added to the system. ${ }^{9}$ This tradeoff is partly driven by the technology's status as a renewable resource, particularly in regions and years where RPS requirements are motivating additional solar capacity and where both UPV and DPV count towards RPS requirements. ${ }^{10}$ More generally, UPV and DPV tend to substitute for one another due to the similarity between the energy and capacity services the two resources provide.

To illustrate this trend, Figure 4 and Figure 5 show results for the scenario in which DPV increases by $5 \%$ penetration by year 15 . Figure 4 shows the cumulative capacities of all technologies across a range of misforecasts, whereas Figure 5 more directly illustrates the impact of DPV misforecasting by showing the differences in capacity additions between each DPV misforecasting scenario and the scenario in which DPV is correctly forecasted.

Both figures illustrate the influence that DPV forecast error has on generation capacity expansion, particularly on UPV capacity additions. For example, from years 11 through 15, a 100\% systematic overforecast of DPV results in 19.5 GW less UPV capacity and 1.4 GW more CT capacity; because

\footnotetext{
${ }^{9}$ We observed this tradeoff across a wide range of scenarios with varying assumptions about DPV penetration, load growth, and natural gas prices. However, we did not exhaustively characterize the persistence of this dynamic, and there may be technology or price environments in which this tradeoff is either notably weaker or absent altogether. For example, we would expect this tradeoff to be weaker if PV prices were higher; if they were high enough that UPV is built only to satisfy technology-specific RPS requirements, then the effect would mostly disappear.

${ }^{10}$ Across all states in the Western Interconnection, RPM treats DPV generation as reducing retail sales of electricity, thereby reducing RPS obligations (which are denominated as a percentage of retail sales). In addition, in all states other than California, RECs from DPV generation also directly contribute to RPS compliance; however, statespecific REC rules are enforced, such as restrictions on which states can either buy or sell RECs from each other.
} 
substantial DPV generation was anticipated, much less UPV capacity is procured. Conversely, underforecasting by $-100 \%$ results in $13.3 \mathrm{GW}$ more UPV capacity, $2.8 \mathrm{GW}$ less natural gas combinedcycle (CC) capacity, and 1 GW more CT capacity. The target amount of total PV generation is approximately the same across each misforecast scenario. Appendix A provides additional results for different DPV penetration scenarios.

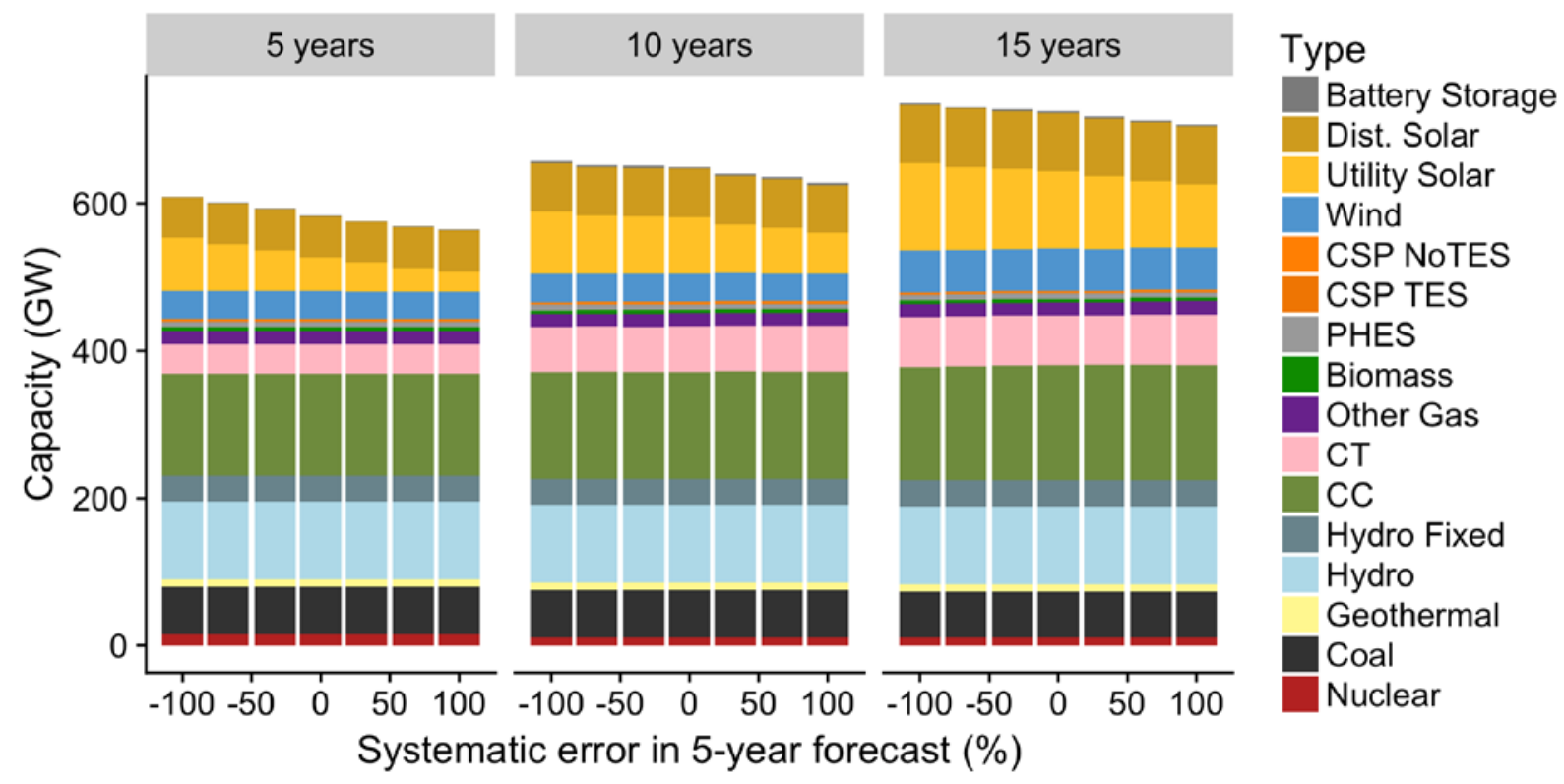

Figure 4. Influence of forecast error on cumulative capacity for the scenario with DPV growth over 15 years equal to $5 \%$ of total generation ${ }^{11}$

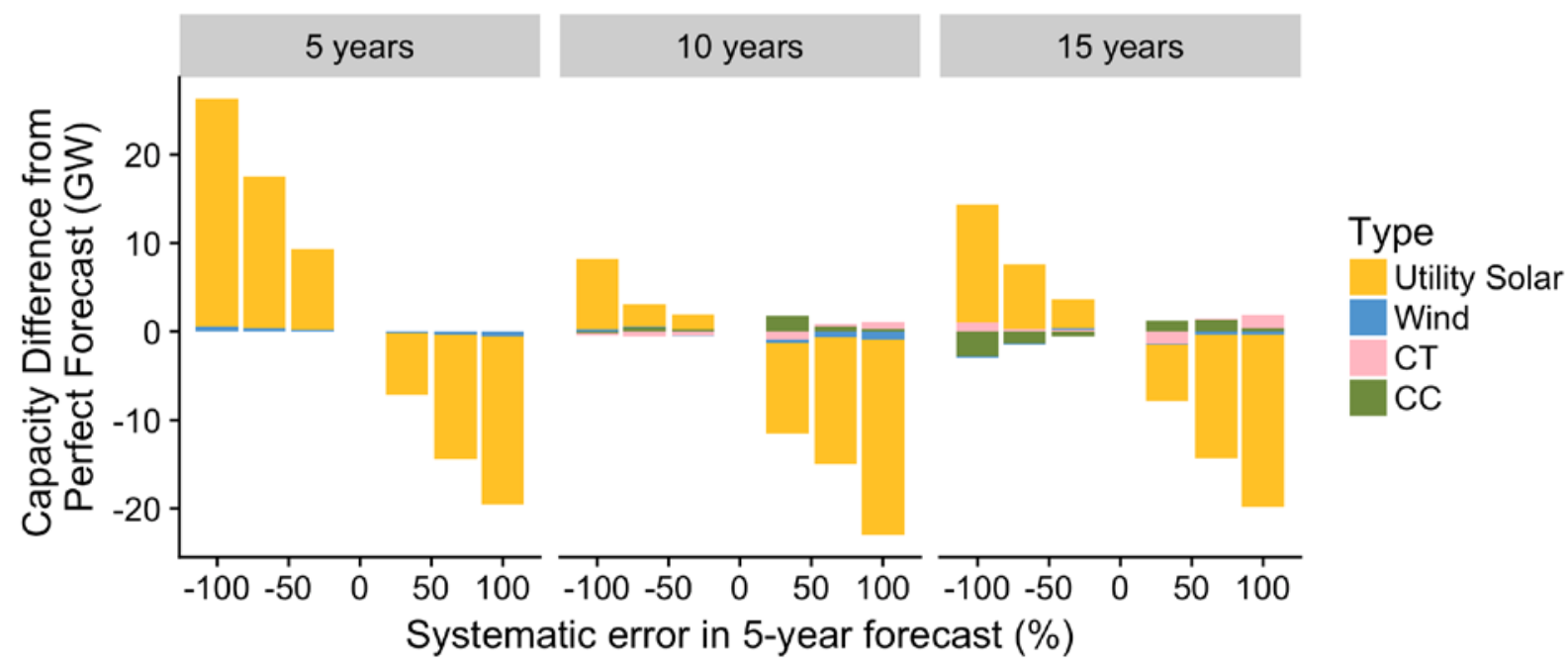

Figure 5. Difference between each technology's cumulative capacities under a range of DPV forecast errors and their cumulative capacity under perfect forecast, for the scenario with DPV growth over 15 years equal to $5 \%$ of total generation

\footnotetext{
${ }^{11}$ CSP is concentrating solar power, either with or without thermal energy storage (TES). PHES is pumped heat electrical storage. Hydro is separated by capacity whose generation is fixed (e.g., run-of-river) and that which is dispatchable. CT is natural gas combustion turbine, and CC is combined-cycle natural gas turbine.
} 
Figure 5 also represents a broader trend observed between different years in the analysis. Through year 5 (2020 in absolute terms), the Western Interconnection is still relatively long on capacity, meaning that UPV capacity is primarily being built to meet RPS or energy requirements. This results in a more direct tradeoff between UPV and DPV. In later years, load growth results in the need for more capacity, and RPS requirements are less frequently binding, resulting in greater impacts on other technologies. Those impacts on technologies other than UPV are highly dependent on the particular system, as well as on the technology cost and performance assumptions at the time capacity-expansion decisions are being made.

\subsection{IMPACT OF FORECAST ERROR ON CAPITAL AND OPERATING COSTS}

We group costs into two broad categories: capital and operating costs. For the purpose of this analysis, capital costs include the initial capital expenditures to build new utility-scale generation and transmission capacity, as well as fixed operations and maintenance (O\&M) costs that do not vary with plant output. Operating costs are those costs incurred as a result of a plant's operation, such as fuel, variable O\&M, and startup costs.

Following from the trends shown in Section 3.1, underforecasting DPV adoption results in greater capital costs due to the greater amount of grid-scale generation capacity additions (primarily UPV), while overforecasting DPV adoption correspondingly results in lower capital costs. ${ }^{12}$ This is illustrated in the left panel of Figure 6, which shows the present value of all capital costs for the Western Interconnection through year 15, across a range of DPV forecast errors and for three different DPV penetration scenarios. The sensitivity of capital costs to DPV misforecasting (i.e., the slope of the lines) is naturally greater for higher DPV penetration levels, because a given percentage misforecast equates to a greater absolute forecast error and thus a greater absolute impact on capacity additions over the planning period.

DPV misforecasting has the opposite effect on operating costs as on capital costs - that is, underforecasting DPV results in lower operating costs, and overforecasting results in higher operating costs, as shown in the right panel of Figure 6. This occurs because the grid-scale capacity additions impacted by DPV misforecasting - primarily UPV in this analysis - have low operating costs compared to the existing fleet. Thus, when DPV is overforecasted and less UPV is built than would have occurred under an accurate forecast, operating costs increase owing to additional fuel consumed by generators needed to compensate for the DPV energy that was expected but did not materialize. Conversely, when DPV is underforecasted and extra UPV is built, operating costs are lower. ${ }^{13,14}$

The trends shown in Figure 6 are closely linked to the tradeoff in the capacity-expansion model between DPV and UPV. Under different modeling conditions in which DPV misforecasting primarily impacts

\footnotetext{
${ }^{12}$ To be sure, DPV systems do entail capital and O\&M costs, but those costs are primarily borne by the owners of the systems, not by the utility — and the focus of this analysis is on costs to the utility system, particularly on costs related to bulk power system planning.

${ }^{13}$ Additional costs can be associated with operating a system that was built under an incorrect DPV forecast. For example, startup costs could be higher if DPV was underforecasted and flexibility is lower than otherwise might have been planned for. Such impacts are generally much smaller than the broader tradeoff described above. RPM does not capture differences in starting units, but PLEXOS includes unit commitment and calculates the impact of startups and partial heat rates.

${ }^{14}$ In general, scenarios with more DPV see greater changes to operating costs for a particular misforecast value compared with scenarios with less DPV (e.g., the slope of the $+5 \%$ DPV scenarios compared to the slope of the $+1.5 \%$ DPV scenarios). When comparing the $+8.5 \%$ and $+5 \%$ overforecasting scenarios, however, this trend does not hold, because the $+8.5 \%$ and $+5 \%$ scenarios have similar impacts on operating costs. Owing to time constraints, we were unable to develop and test an explanation for this apparent saturation of operating cost impacts.
} 
natural gas-fired capacity additions, rather than UPV, we would expect to see weaker but qualitatively similar trends. New gas-fired plants generally have lower heat rates and thus lower operating costs than existing plants. Underforecasting DPV would thus result in an oversupply of new gas-fired additionshence higher capital costs and lower operating costs, compared to what would occur if DPV adoption were perfectly forecast. The converse would occur with an overforecast of DPV adoption.
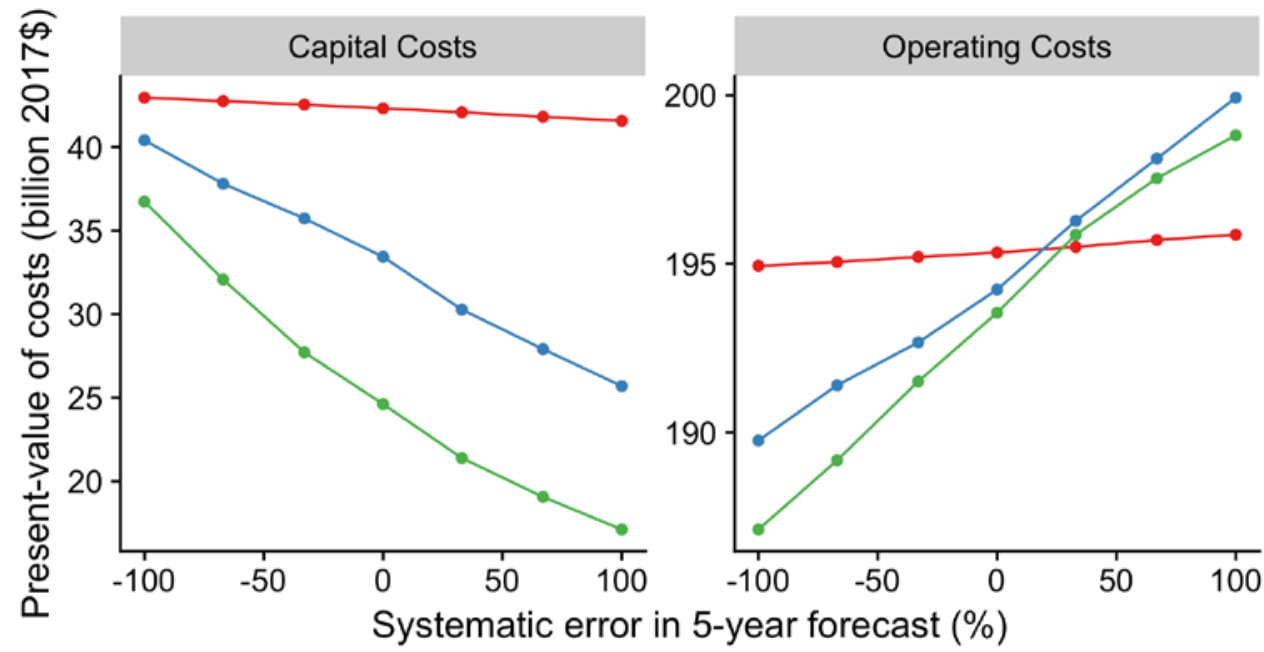

15-year Increase in DPV

$\rightarrow+1.5 \% \mathrm{DPV}$

$\rightarrow+5.0 \%$ DPV

$\longrightarrow+8.5 \%$ DPV

Figure 6. Impact of forecast error on the net present value (NPV) of capital and operating costs through year 15, prior to reserve margin or RPS adjustments

These cost implications are not the only impacts of DPV forecast error, however. As mentioned in the methods section, the system is planned to be least-cost while procuring sufficient firm capacity to meet peak load plus a reserve margin as well as ensuring that a certain fraction of sales is met by qualifying technologies, as required by state RPS. If DPV is overforecasted, the system may not meet either or both of these requirements. Thus, we include adjustments to estimate the additional costs that may be incurred when procuring resources to make up for any potential shortfalls.

As shown in Figure 7, overforecasting DPV results in the system reserve margin not being met, whereas underforecasting results in capacity that exceeds what is necessary. The primary cause is relatively straightforward - the system was optimized to just meet the reserve margin while anticipating a certain amount of new DPV, so any deviation in the contribution of that resource will have a corresponding influence on the system's reserve margin. ${ }^{15}$ Similarly, if the utility counts on DPV RECs to meet its RPS requirements, then the same trend is observed-overforecasting DPV results in less renewable generation than was expected, thus potentially resulting in a shortfall, whereas underforecasting DPV results in more

\footnotetext{
${ }^{15}$ RPM accounts for variable and distributed resources in its planning reserve margin constraint, where the capacity value of UPV, DPV, wind, and other variable energy technologies are endogenously estimated based on the amount and location of deployment (Hale et al. 2016). The estimated capacity values reflect the contribution of these technologies to planning reserve requirements, which we estimate for each of four North American Electric Reliability Corporation (NERC) assessment areas in the U.S. portion of the Western Interconnection at reserve margin requirements of $13.9 \%-21 \%$ and a Western Interconnection-wide average of $17.6 \%$. The four assessment regions include Northwest Power Pool (NWPP), Rocky Mountain Reserve Group (RMRG), Western Electricity Coordinating Council/California (CAMX), and Southwest Reserve Sharing Group (SRSG) (see http://www.nerc.com/AboutNERC/keyplayers/PublishingImages/NERC_Assessment_Areas_2016.jpg).

NWPP_CAN is also included for western Canada. However, DPV projections are not included for that NERC region. While RPM exactly meets these NERC-wide requirements, historically most regions have capacity in excess of these requirements.
} 
renewable generation than was planned for. If a utility does not include DPV RECs in its RPS compliance planning, then the impact of misforecasting on those particular costs is mitigated.

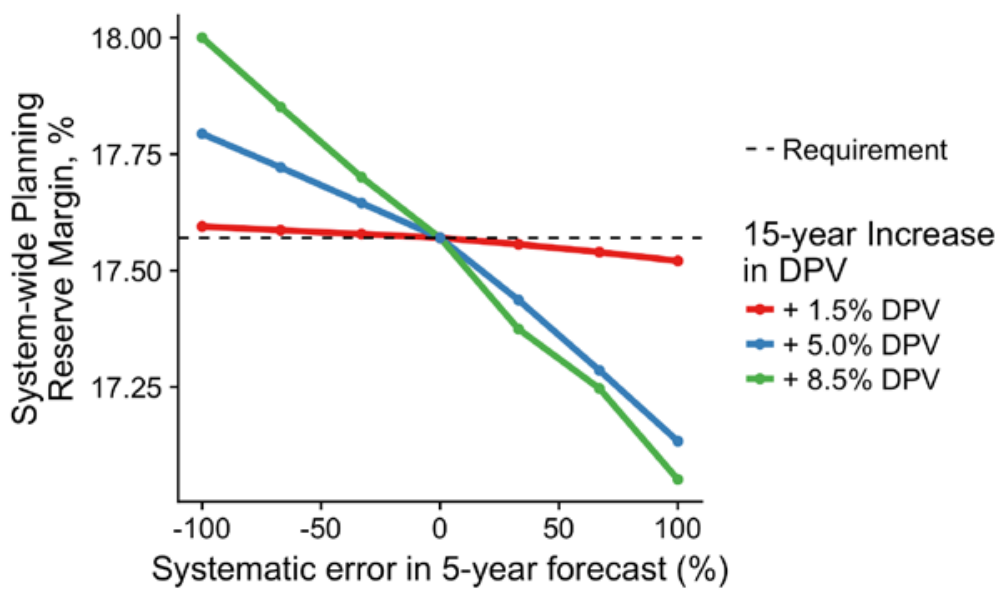

Figure 7. Effect of DPV forecast error on planning reserve margin in year 15

Figure 8 shows our adjustments for these two costs, added to the values previously shown in Figure 6. The reliability (reserve margin) adjustment is added to capital costs, whereas the RPS adjustment is added to operating costs. Both adjustments tend to increase as the absolute level of forecast error increases, and reliability impacts are greater than RPS impacts under our assumptions. Section 3.4 shows the sensitivity of our cost results to REC price variations.
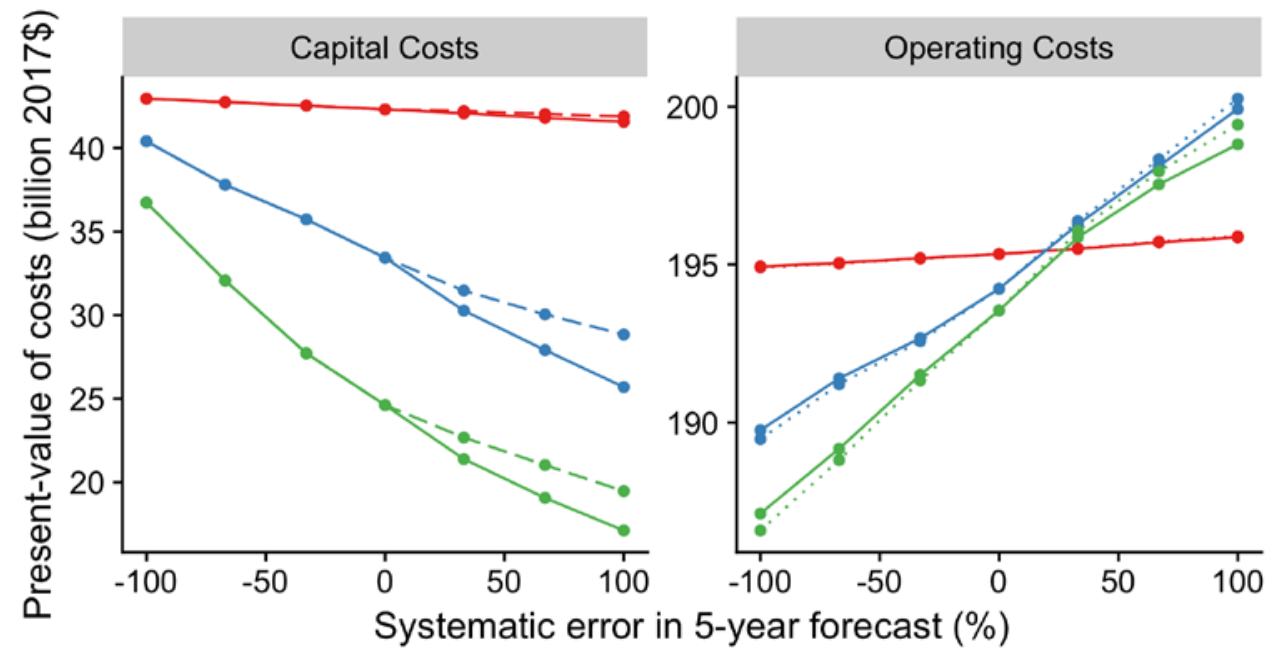

15-year Increase in DPV

$\rightarrow+1.5 \%$ DPV

$\longrightarrow+5.0 \%$ DPV

$\longrightarrow+8.5 \%$ DPV

Correction Type

- None

$--\cdot$ Reliability

..... RPS

Figure 8. Impact of reliability and RPS adjustments on the NPV of capital and operating costs through year 15 (figure scales are different for capital and operating costs)

\subsection{NORMALIZED IMPACT OF DPV FORECAST ERROR ON TOTAL COSTS AND VALUE OF IMPROVED DPV ADOPTION FORECASTS}

Figure 9 displays the total present-value cost of forecast error-including capital and operating costs—as a function of the severity of the systematic error and increase in DPV energy penetration by the end of year 15, for the entire Western Interconnection. The figure's "heat map” design enables visualization of continuous variation in all parameters. Unlike the results in Section 3.2, the costs shown in Figure 9 are 
not absolute costs, but rather the differences between total system costs when there is forecast error and total system costs without error. The cost difference is then normalized by total annual electricity sales in the Western Interconnection in the starting year (2015), to enable extrapolation of these regional average impacts onto other regions (with the caveats discussed more fully below). ${ }^{16}$

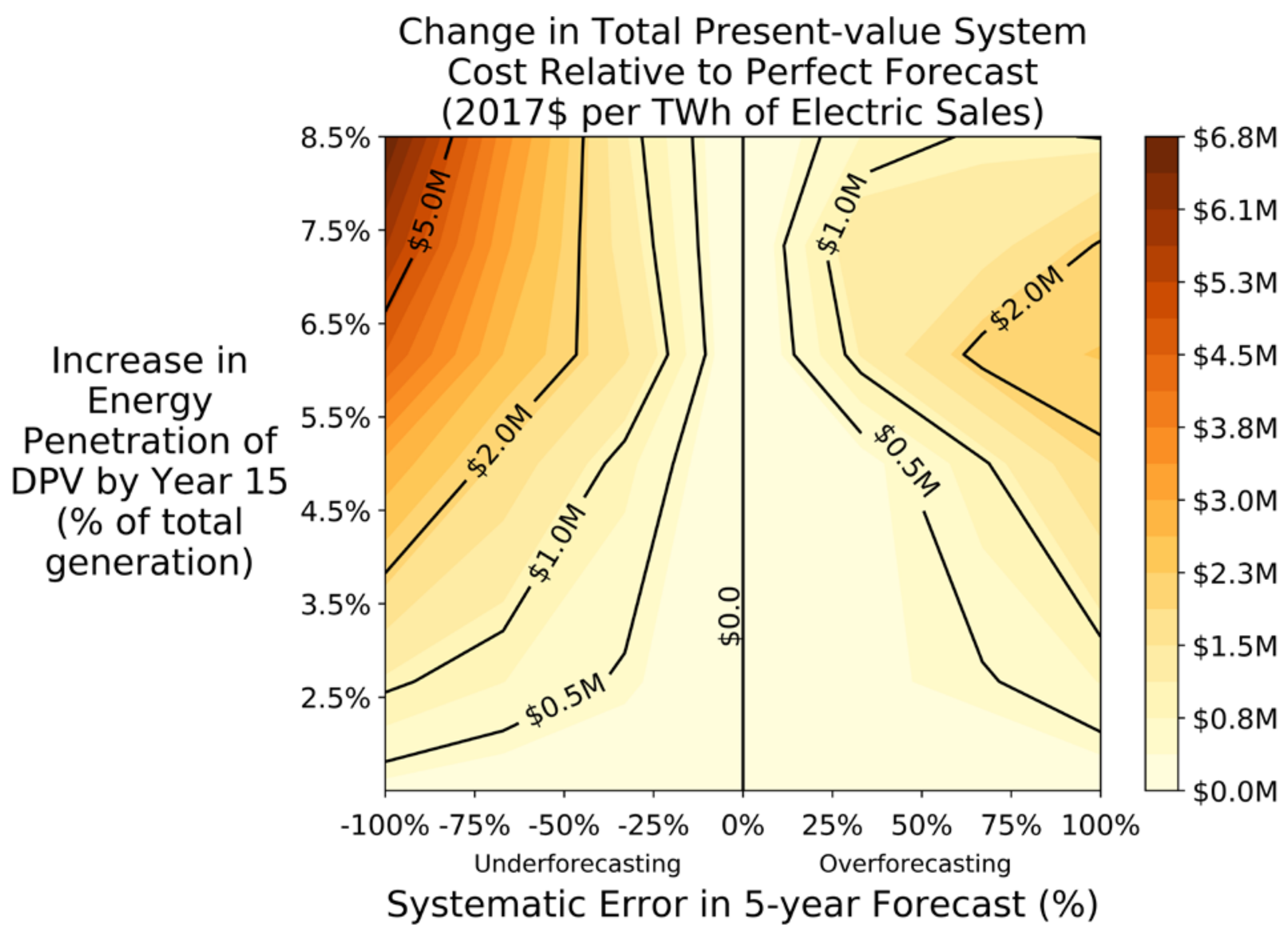

Figure 9. Normalized total present-value costs due to systematic DPV misforecasts in the Western Interconnection through year 15

As shown in Figure 9, the present value of the cost of forecast error reaches nearly $\$ 7$ million per TWh of electric sales when DPV adoption is severely underforecasted, and more than \$2 million/TWh when DPV adoption is severely overforecasted. These upper-end cost impacts correspond to relatively high levels of DPV adoption (6.5\%-8.5\% of total energy generation over 15 years) and relatively severe levels of misforecasting ( $\pm 100 \%$ forecast error). Naturally, when DPV growth is lower, or when DPV forecast error is less severe, the cost of misforecasting may be substantially less. ${ }^{17}$ For example, with DPV growth equal to just $2 \%$ of total energy generation or forecasting errors of just $\pm 25 \%$, the cost of misforecasting is less than $\$ 1$ million per TWh. The results in Figure 9 also suggest that underforecasting has greater cost impacts than does an equivalent degree of overforecasting; however, some caution is warranted in

\footnotetext{
${ }^{16}$ As mentioned in the Executive Summary, our metric_-millions of 2017\$ per TWh of electric sales-should not be confused with the more common metrics of $\$ / \mathrm{MWh}$ or $\$ / \mathrm{kWh}$. Our metric is the present value of a 15-year cash flow, whereas the more common metrics are instantaneous or average values.

${ }^{17}$ Curiously, the costs from overforecasting peak at around an increase of 6.5\% DPV and then decline as DPV increases further. This trend was not consistently observed across sensitivity cases, and it should be considered an idiosyncratic (and not generalizable) result.
} 
generalizing from that trend, because sensitivity scenarios (e.g., with higher REC prices) show this relationship can be reversed.

These electric-sales-normalized cost estimates can be applied to specific utility systems, based on retail sales volume, to provide a first-order estimate of the potential cost of DPV adoption forecasting errors. ${ }^{18}$ Of approximately 1,800 U.S. utilities, the largest in terms of bundled retail electricity sales is Florida Power \& Light at $110 \mathrm{TWh} /$ year, and the largest in the Western Interconnection is Southern California Edison at $75 \mathrm{TWh} /$ year. ${ }^{19}$ The average size is much smaller-only $1.5 \mathrm{TWh} /$ year. Sixty-seven utilities have sales that exceed $10 \mathrm{TWh} /$ year, a convenient demarcation for what we might call a "large" utility. For a utility of that size and with DPV penetration potentially increasing by $8.5 \%$ of sales by the end of a 15 -year period, our results translate to a present-value cost of roughly $\$ 70$ million from severe underforecasting and \$20 million from severe overforecasting. A present-value cost of $\$ 70$ million would equate to a roughly $0.5 \%$ increase in total utility costs for a 10 -TWh/year utility. ${ }^{20}$

\section{Estimating the Value of Improved DPV Adoption Forecasts}

The estimates given above represent potential costs due to a single specified DPV forecasting error and increase in DPV energy penetration, relative to a perfect forecast. However, no improvement in DPV adoption forecasting would be expected to eliminate these costs completely. Rather, a utility interested in evaluating the potential benefits from improving its DPV adoption forecasts would need to compare the current expected costs from forecast errors against the expected costs under a situation with reduced forecast error.

As one approach, a utility could stipulate probabilities for a discrete set of future DPV penetration increases. Based on those assumptions, it could use the results in Figure 9 to calculate the expected cost of DPV forecasting error. It would then repeat the same calculation, but with a narrower range in forecast error to reflect improved DPV forecasting, and the difference between the two probability-weighted expected costs would represent the value of the reduced DPV forecast error.

As a simplified example, consider a utility with $10 \mathrm{TWh} /$ year of retail electricity sales. With its current DPV forecasting capabilities, it is planning for an increase of 3.5\% DPV penetration. It assigns a 50\% probability to this trajectory, but it assigns a $25 \%$ probability that penetration will only increase by $2 \%$ and a $25 \%$ probability that penetration will increase by $7.5 \%$. These lower- and upper-bound penetration levels correspond to forecast errors of $75 \%$ and $-53 \%$, respectively. This combination of DPV penetration increases and forecast errors corresponds to Line A in Figure 10. Given these assumptions, the expected cost of DPV misforecasting for this utility would be \$6.9 million.

\footnotetext{
${ }^{18}$ Mapping Western Interconnection-wide results onto smaller entities assumes the cost of misforecasting DPV adoption scales with the size of the planning region. This is perhaps a reasonable first-order assumption in the absence of detailed modeling, but certainly these impacts would be influenced by any individual utility or planning region. The Western Interconnection is a large system with diverse flexibility and resource options but limited ability to trade with neighbors. The results for a smaller or otherwise different system would vary according to that system's characteristics - for example, more trading opportunities would likely reduce the costs of forecast error, whereas a less flexible initial system would likely increase costs.

${ }^{19}$ These numbers are from the EIA's Sales to Ultimate Customer data for 2015 (EIA 2017b) and only include the bundled sale of electricity; they do not include entities that report as being behind-the-meter or retail power marketers.

${ }^{20}$ The total utility cost over this period is estimated assuming an initial all-in cost of electricity of $10.4 \mathrm{~d} / \mathrm{kWh}$ and a real escalation rate of $0.4 \% /$ year, load growth of $1 \% /$ year, and a real discount rate of $5.44 \%$.
} 
Suppose the utility is then considering an improvement to its DPV forecasting capabilities that it expects would reduce the forecast error to $\pm 25 \%$ (Line B in Figure 10). Repeating the same set of calculations as above, this would reduce the expected cost of DPV misforecasting to $\$ 2.9$ million, resulting in savings of $\$ 4.0$ million. A more detailed explanation of this example and the underlying steps in the calculations is provided in Appendix B. If the utility believes the total present-value cost of the tools, training, or personnel required to achieve that degree of forecasting accuracy is significantly less than the expected cost savings, then it may be financially prudent to make the investment. As one point of reference, the fully burdened present-value cost of a full-time analyst over 15 years is approximately $\$ 2.5$ million. ${ }^{21}$

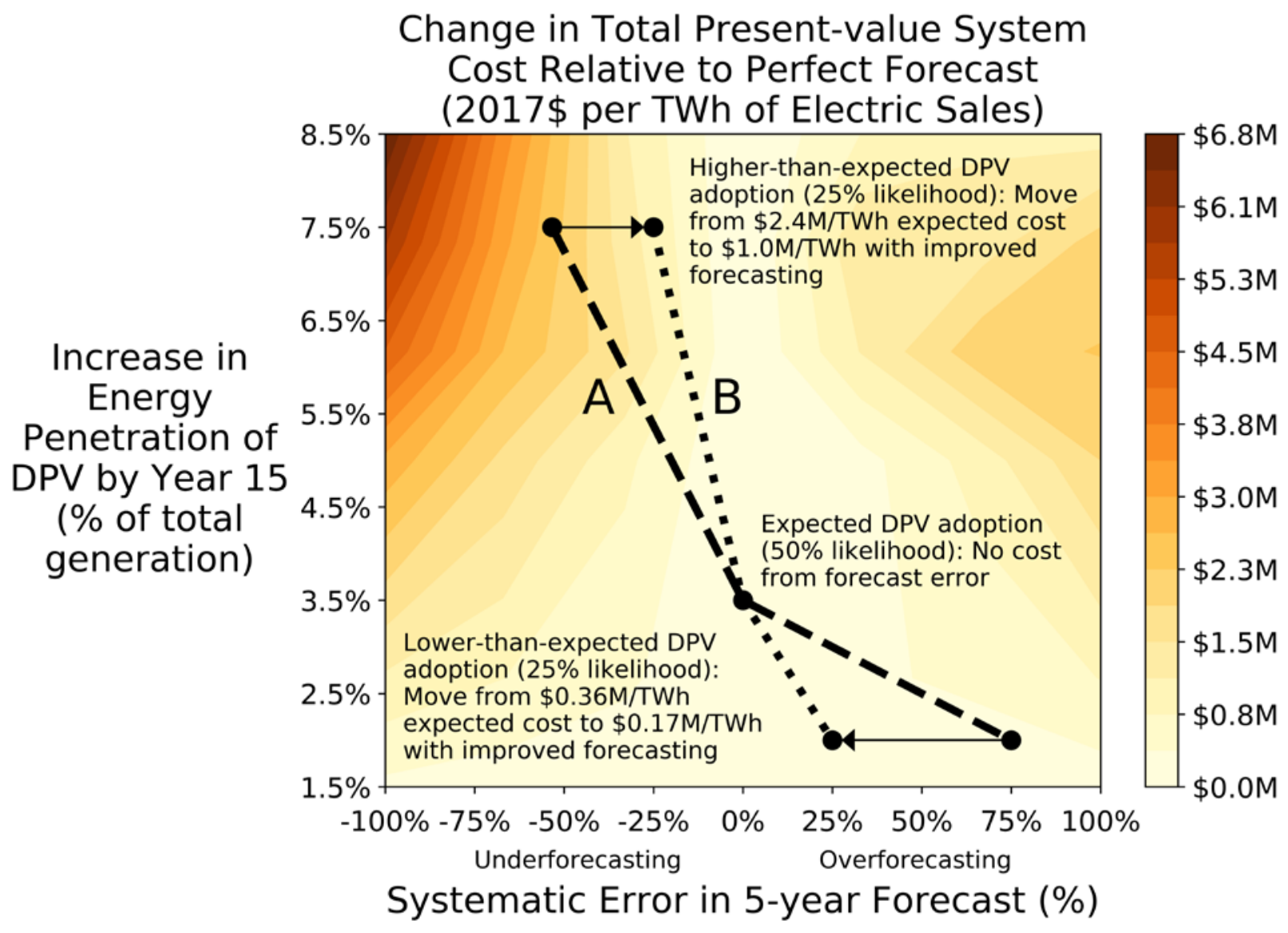

Figure 10. Illustration of cost savings from improving DPV forecasts

Lastly, the method described in this section can also be used to estimate the expected cost if future DPV adoption is wholly neglected in resource planning, which corresponds to a systematic error of $-100 \%{ }^{22}$ In Figure 11, Line A captures potential -100\% error scenarios; for the sake of comparison, the same likelihoods from the preceding example are used. The expected cost of misforecasting under this scenario

\footnotetext{
${ }^{21}$ This is based on a starting fully burdened cost of \$107/hour (per the General Services Administration's data for contracts awarded to analysts with a master's degree and 4 years of experience), a 2\%/year increase in fully burdened cost, and a real discount rate of 5.4\%.

22 This represents a relatively extreme scenario. In some cases, a utility may not explicitly account for future DPV adoption; however, if the utility's load forecast is calibrated to historical data, as is often the case, then the load forecast may nevertheless implicitly account for some amount of future DPV growth (i.e., by implicitly assuming that DPV growth continues at the historical rate).
} 
is $\$ 24.7$ million for a 10-TWh/year entity. Adopting DPV-forecasting capabilities that move the utility to Line B would result in estimated savings of $\$ 21.8$ million.

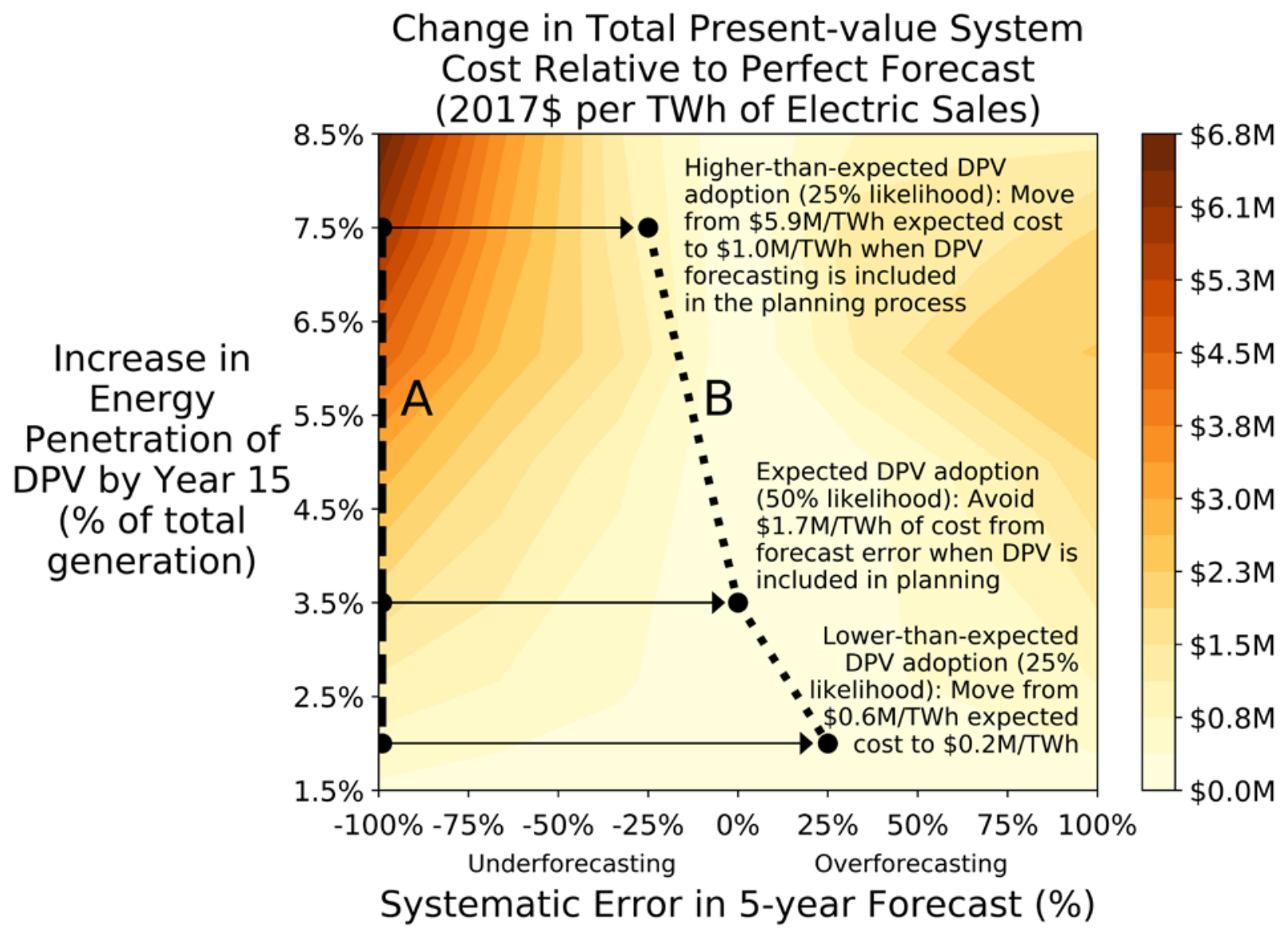

Figure 11. Impact of including improved DPV forecasts into the resource planning process, relative to entirely neglecting future DPV adoption

\subsection{SENSITIVITIES}

To this point, we have explored how the value of improved DPV forecasting is driven by the DPV adoption rate and the severity of the misforecast. This subsection examines how the results are influenced by three factors related to the broader planning environment: load growth, natural gas prices, and REC prices. Other market, policy, and technology assumptions could also impact the results-for example, different PV cost trajectories or the introduction of new disruptive technologies—but, for the sake of tractability, are not explored here.

Figure 12 shows the sensitivity of the results to these factors, quantified as the difference in total system cost between each misforecast scenario and the scenario with no forecast error. Each panel shows the results for different amounts of DPV increases by the end of year 15, and the x-axes show the range of misforecast severity. The sensitivity results for the low DPV growth case (when DPV penetration increases by only $1.5 \%$ of total generation) are not particularly revealing, as the cost of misforecasting is small across all sensitivity cases. We therefore focus our discussion on the two scenarios with higher DPV penetrations, in which DPV generation grows by 5\% and 8.5\% of total generation over the 15-year planning period. The total costs shown in Figure 12 are broken down into capital and operating costs in Appendix D. 


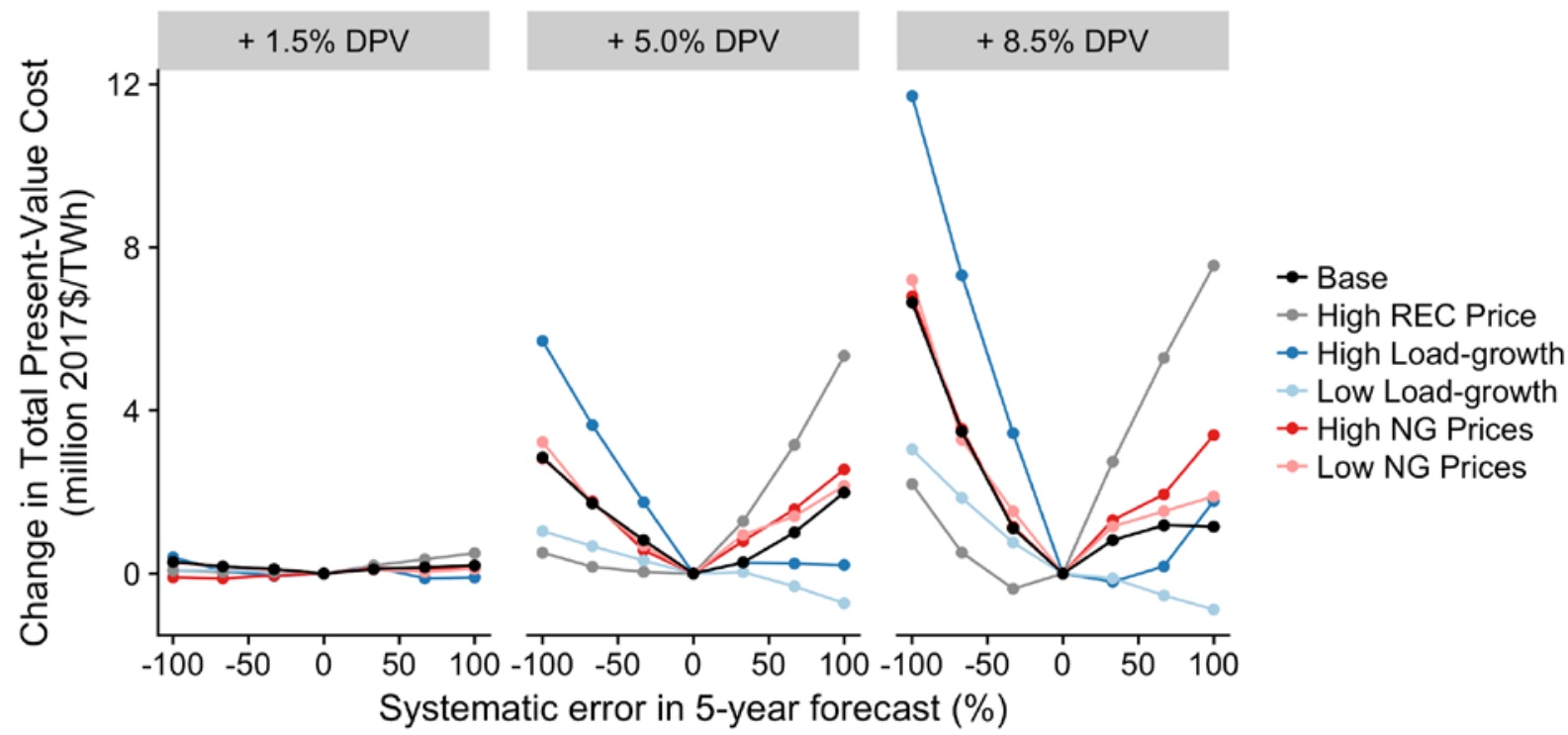

Figure 12. Sensitivity of change in total present-value system costs (relative to perfect forecast) to load growth rates, natural gas (NG) prices, and REC prices

REC Prices: As previously discussed, we add or subtract costs for shortfalls or excesses of RECs from DPV generation-implicitly assuming that the utility was counting on obtaining those RECs for RPS compliance. While our base scenario assumes REC prices of $\$ 1-\$ 3 / \mathrm{MWh}$, the High REC price scenario uses a value of $\$ 22 / \mathrm{MWh} .^{23}$

The results of this sensitivity analysis have divergent implications for the cost of misforecasting DPV, depending on whether it is an overforecast or an underforecast. When DPV is overforecasted, higher REC prices significantly increase the cost of misforecasting DPV. This is driven by the need to purchase relatively expensive RECs to meet state RPS requirements after DPV adoption falls short of expectations. Naturally, these impacts are most pronounced when the utility would otherwise just barely meet its RPS requirement, such that a DPV overforecast would cause the utility to fall short of its RPS requirement. In contrast, when DPV is underforecasted, the utility ends up with excess RECs that it can sell; high REC prices can significantly increase the revenues from those sales, thereby mitigating the costs of misforecasting. Under the $+5 \%$ DPV scenario, the revenues from excess REC sales almost exactly offset the cost of misforecasting, resulting in effectively zero net cost when DPV growth is underforecasted. ${ }^{24}$ Note that, if a utility does not count on obtaining DPV RECs as part of its RPS compliance plan, then the cost adjustments described in this scenario would not occur.

Natural Gas Prices: Our base scenario uses natural gas prices from the EIA’s 2016 Annual Energy Outlook Reference scenario, whereas our high and low natural gas price sensitivity cases use gas prices

\footnotetext{
${ }^{23}$ The value \$22/MWh is the median price observed in RPM for the first year under the conditions of the base scenario used in this analysis. The prices in the first year are higher than in subsequent years because renewable technology prices are higher and the supply of RECs is more constrained. The value $\$ 22 / \mathrm{MWh}$ is not an upper limit to REC prices, because higher prices have been observed in practice.

${ }^{24}$ Under the $+8.5 \%$ DPV scenario, a minor underforecast reduces costs slightly compared with a perfect forecast. This occurs because RPM found the least-cost expansion of the entire Western Interconnection in our core workflow, with the adjustments for buying or selling RECs from misforecasting added in post-processing. The REC transactions effectively created another revenue opportunity that was not available to RPM during the model's capacity-expansion analysis.
} 
from the EIA's Low and High Oil and Gas Resource scenarios (EIA 2016). These trajectories are shown in Figure 13.

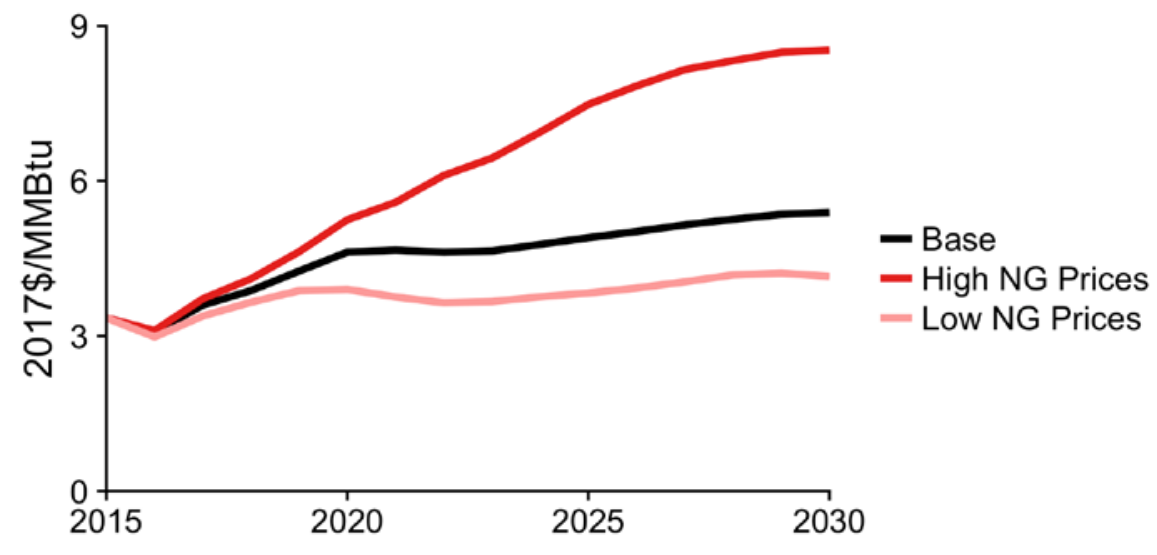

Figure 13. Natural gas price assumptions

In the first 5 years of the analysis period, natural gas prices have a consistent and predictable impact on the costs of misforecasting. High natural gas prices increase the cost of overforecasting and decrease the cost of underforecasting, because DPV misforecasting influences how much gas-combustion generation occurs. Later-year changes in capital investments cancel out this trend, however, resulting in total presentvalue costs that are relatively insensitive to gas prices. The exact changes vary considerably across the Western Interconnection and thus are difficult to generalize.

Load Growth: Our base scenario uses load growth values from the Western Electricity Coordinating Council's Transmission Expansion Planning Policy Committee (TEPPC) for each balancing area, yielding a total Western Interconnection growth rate of 1.25\% annually. Our high and low load growth scenarios add and subtract $1 \%$ from each balancing area's projected annual growth rate. For comparison purposes, we hold the absolute amount of DPV adoption fixed across the load growth sensitivities, compared to the corresponding base scenario. Focusing first on the sensitivity to load growth when DPV is underforecasted, Figure 12 shows that the cost of misforecasting tends to be larger with high load growth and smaller with low load growth. These results are driven by the impact of load growth on reserve margins: high load growth causes the Western Interconnection to become capacity constrained earlier in the analysis period, leading to more pronounced impacts of DPV misforecasting on capacity costs. The sensitivity results when DPV is overforecasted are somewhat less intuitive, because the costs of misforecasting are lower than in the base case under both the high and low load growth sensitivities. These counterintuitive results are an idiosyncratic feature of the particular study region and period, and they are driven by the complex interactions between reserve margins and path-dependent capacityexpansion decisions.

Altogether, the sensitivities explored have a range of impacts, in some cases as much as doubling and in other cases significantly reducing the costs of misforecasting. This analysis suggests our base scenario is a reasonable, central starting point for estimating the value of improved forecasting capability — but from such an initial estimate, it would be prudent to ask whether adjustment should be made for key differences in environmental conditions or the unique characteristics of the utility system in question. 


\section{Impact of considering DPV's capacity value during capacity-expansion planning}

Forecasting is only one opportunity area for improved consideration of DPV in utility planning. Mills et al. (2016) highlight nine methodological elements for which innovative practices exist for incorporating DPV into utility planning, including "incorporating the non-dispatchability of DPV into planning methods" and "considering changes in costs and benefits of DPV with higher solar penetration." In this text box, we focus only on the treatment of DPV's capacity value (CV) and demonstrate how omitting DPV's CV can affect capacity-expansion choices and system costs.

$\mathrm{CV}$ is the fraction of generator nameplate capacity that can be relied on to contribute to peak generation needs for resource adequacy purposes. DPV CV reflects the fractional expected amount of (net) peak load reduction from an increment of DPV capacity adoption. RPM endogenously estimates CV based on DPV penetration and location. It applies these calculations to all variable generation technologies and uses the estimates to inform planning reserve capacity needs in its portfolio optimization. For example, the average marginal CV of DPV is estimated at $29.7 \%$ in the $5^{\text {th }}$ year (2020), but that declines to an average of $4.6 \%$ by the $15^{\text {th }}$ year (2030) in the scenario with an increase of $8.5 \%$ DPV energy penetration (10\% in total), with a wide range for all years depending on location.

For this sensitivity analysis, we model DPV as having zero CV, implying that the utility's planning method does not account for DPV's CV, or the utility does not expect DPV to contribute to reducing peak capacity needs. The left panel of Figure 14 shows the differences in year-15 generation capacity caused by assuming zero DPV CV, compared with using DPV CVs calculated endogenously by RPM, for three DPV penetration scenarios. Ignoring DPV's CV results in an increased need for new capacity and, potentially, higher capacity prices. The preferred portfolio is altered, and-although specific portfolio changes are sensitive to input assumptions-the results indicate that omitting DPV's CV favors technologies that have higher ratios of capacity-to-energy value (e.g., UPV over wind). More importantly, the right panel of Figure 14 shows that this CV omission can result in higher system costs. In fact, the incremental costs are similar to or even greater than the costs of misforecasting estimated in this report. The CV sensitivity scenarios presented here assume perfect forecasting, but misforecasting can compound the effects. This example highlights the value of incorporating many of DPV's unique characteristics into utility planning processes as discussed in Mills et al. (2016).
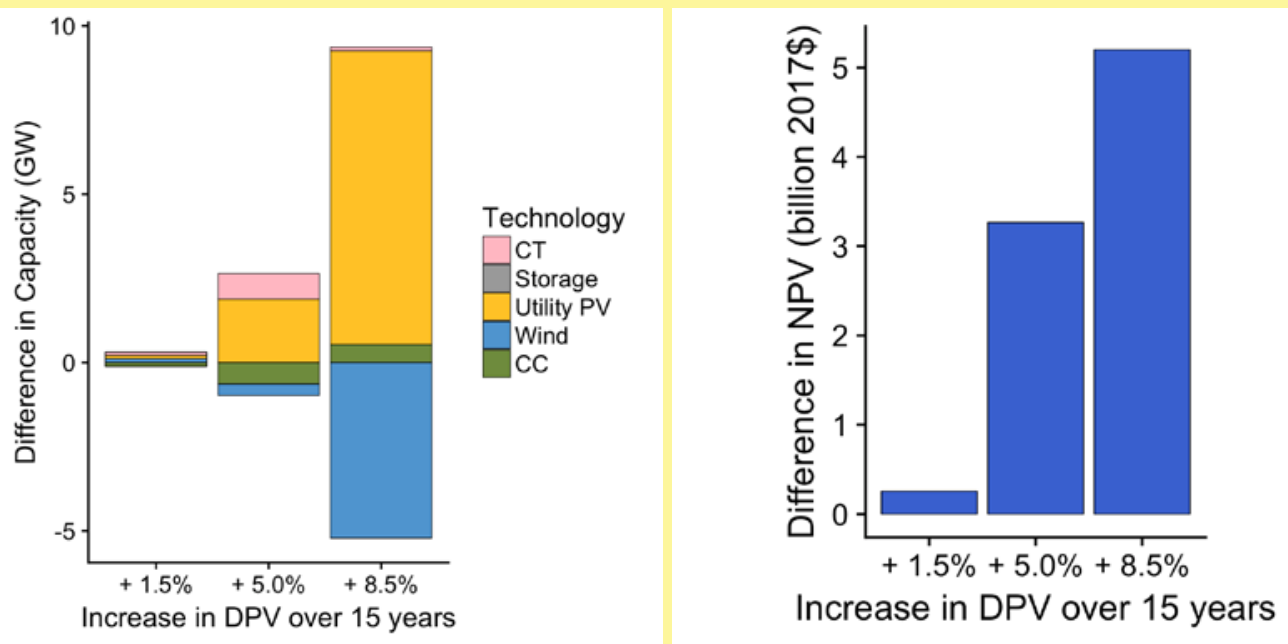

Figure 14. Difference in 2030 system capacity (left) and system cost NPV (right) caused by omitting the CV of DPV during capacity-expansion planning, values are for the entire Western Interconnection 


\section{ConcLusions}

Current utility resource planning practices vary widely in terms of the sophistication of their approach to forecasting future DPV adoption, and the state-of-the-art in DPV adoption forecasting is undergoing continuous refinement. Utility resource planners may have an interest in improving the DPV forecasting techniques used within their planning studies, because reducing the uncertainty in those forecasts may enable more-optimized resource plans and thus ultimately lower the costs to build and operate their system. However, implementing such improvements entails costs related to new tools, training, staffing, or contractors. Assessing whether such investments are worthwhile therefore requires some understanding of the potential benefits (i.e., future cost savings) associated with improved DPV adoption forecasting.

This report informs these tradeoffs by estimating how reducing uncertainty in DPV adoption forecasts used in utility resource plans can reduce future utility capital and operating costs. This analysis focuses specifically on the Western Interconnection and considers only the impacts on capital and operating costs associated with the bulk power system (i.e., it does not consider the effects of DPV forecasting error on distribution system costs). Those limitations in study scope notwithstanding, the analysis reveals several key findings and themes:

- The utility-cost impacts of misforecasting DPV adoption can be non-trivial. Within our base-case analysis, updating resource plans for DPV adoption once every 5 years while neglecting future adoption in resource plans over a 15-year period increases the present value of utility system costs by up to $\$ 7$ million per TWh of electricity sales, relative to utility system costs if DPV forecasting were perfect. This would equate to an increase in total costs of about $0.5 \%$. Naturally, the cost impacts are less acute in cases with less DPV growth or a smaller degree of misforecasting. For example, for a utility with DPV growth equal to just $2 \%$ of total energy generation over 15 years or a forecasting error of just $\pm 25 \%$, the cost of misforecasting is less than $\$ 1$ million per TWh of electricity sales, within our analysis.

- The cost of misforecasting can be asymmetrical. The cost impact cited above (\$7 million per TWh of retail sales) corresponds to a scenario with severe underforecasting of future DPV generation. In contrast, the costliest overforecasting increases utility system costs by just $\$ 2$ million per TWh within our base-case analysis. These particular results are specific to the system modeled in this analysis. In general, underforecasting DPV tends to increase capital costs but decrease operating costs (relative to a perfect forecast), while overforecasting DPV does the opposite. Accordingly, the magnitude and direction of any asymmetry depends on the relative degree of sensitivity of capital and operating costs to DPV forecast error.

- The cost of misforecasting is sensitive to market and planning conditions. The Western Interconnection, as modeled in this analysis, is oversupplied with capacity in the initial years of the planning period. This partially explains the asymmetry between over- and underforecasting observed in our base case, because an initially overbuilt system typically requires less new capacity additions for the initial years of a planning period, and thus overforecasting DPV adoption (i.e., underforecasting load growth) has a muted impact on capacity-expansion decisions. As another example of how specific utility system conditions may impact the cost of misforecasting DPV adoption, our analysis also highlights the importance of REC prices if a utility includes anticipated DPV RECs in its RPS compliance planning. In a sensitivity case with roughly a \$20/MWh increase in REC prices, the cost of severely overforecasting DPV in the high-DPV case rises from $\$ 1$ million per TWh of retail sales in the base case to roughly $\$ 8$ million. This is due to the additional cost of having to purchase RECs to cover RPS compliance shortfalls. Conversely, the cost of severely underforecasting DPV falls from \$7 million per TWh to \$2 million due to the additional revenues from the sale of surplus RECs. 
The quantitative estimates developed in this report are based on a specific electric system and period, and they rely on a host of assumptions about market and policy conditions during that period. Using our simplified probabilistic method, analysts can make first-order estimates of the potential cost savings from improved DPV forecasts. Naturally, these estimates are most useful if followed by a robust examination of how each analyst's unique circumstances may deviate from the environment assumed in our modeling. That said, we hope the estimates obtainable from this report will offer a useful starting point for planners seeking to evaluate the merits of investing in improved DPV forecasting methods. 


\section{REFERENCES}

Barbose, G. 2017. U.S. Renewable Portfolio Standards: 2017 Annual Status Report. LBNL2001031. Berkeley, CA: Lawrence Berkeley National Laboratory.

BNEF (Bloomberg New Energy Finance). 2016. The Impact of the ITC Extension on US Solar. Analysis prepared for the Solar Energy Industries Association. New York: BNEF.

Cole, W., P. Kurup, M. Hand, D. Feldman, B. Sigrin, E. Lantz, T. Stehly, C. Augustine, C. Turchi, P. O’Connor, and C. Waldoch. 2016a. 2016 Annual Technology Baseline (ATB). NREL/PR-6A20-66944. Golden, CO: National Renewable Energy Laboratory.

Cole, W., T. Mai, J. Logan, D. Steinberg, J. McCall, J. Richards, B. Sigrin, and G. Porro. $2016 b$. 2016 Standard Scenarios Report: A U.S. Electricity Sector Outlook. NREL/TP-6A2066939. Golden, CO: National Renewable Energy Laboratory. http://www.nrel.gov/docs/fy17osti/66939.pdf

Dong, C., and B. Sigrin. 2016. "Willingness-to-Pay for Solar Photovoltaics: A 'Parameterization + Calibration’ Approach.” Working Paper. Golden, CO: National Renewable Energy Laboratory.

EIA (U.S. Energy Information Administration). 2016. Annual Energy Outlook 2016. Washington, DC: EIA.

EIA (U.S. Energy Information Administration). 2017a. Annual Energy Outlook 2017. Washington, DC: EIA.

EIA (U.S. Energy Information Administration). 2017b. Sales to Ultimate Customer 2015. Washington, DC: EIA.

Gagnon, P., R. Margolis, J. Melius, C. Phillips, and R. Elmore. 2016. Rooftop Solar Photovoltaic Technical Potential in the United States: A Detailed Assessment. NREL/TP-6A20-65298. Golden, CO: National Renewable Energy Laboratory.

Gagnon, P., and B. Sigrin. 2016. Distributed PV Adoption-Sensitivity to Market Factors. NREL/PR-6A20-65984. Golden, CO: National Renewable Energy Laboratory.

Hale, E., B. Stoll, and T. Mai. 2016. Capturing the Impact of Storage and Other Flexible Technologies on Electric System Planning. NREL/TP-6A20-65726. Golden, CO: National Renewable Energy Laboratory.

Lew, D., G. Brinkman, E. Ibanez, A. Florita, M. Heaney, B.-M. Hodge, M. Hummon, G. Stark, J. King, S.A. Lefton, N. Kumar, D. Agan, G. Jordan, and S. Venkataraman. 2013. The Western Wind and Solar Integration Study Phase 2. NREL/TP-5500-55588. Golden, CO: National Renewable Energy Laboratory. 
Mills, A., G. Barbose, J. Seel, C. Dong, T. Mai, B. Sigrin, and J. Zuboy. 2016. Planning for a Distributed Disruption: Innovative Practices for Incorporating Distributed Solar into Utility Planning. LBNL-1006047. Berkeley, CA: Lawrence Berkeley National Laboratory.

Rai, V., and S. Robinson. 2015. "Agent-Based Modeling of Energy Technology Adoption: Empirical Integration of Social, Behavioral, Economic, and Environmental Factors.” Environmental Modelling \& Software 70(August): 163-177.

Sigrin, B., M. Gleason, R. Preus, I. Baring-Gould, and R. Margolis. 2016. The Distributed Generation Market Demand Model (dGen): Documentation. NREL/TP-6A20-65231. Golden, CO: National Renewable Energy Laboratory. http://www.nrel.gov/docs/fy16osti/65231.pdf

Zhang, H., Y. Vorobeychik, J. Letchford, and K. Lakkaraju. 2015. "Data-Driven Agent-Based Modeling, with Application to Rooftop Solar Adoption.” In Proceedings of the 2015 International Conference on Autonomous Agents and Multiagent Systems, 513-521. AAMAS'15. Richland, SC: International Foundation for Autonomous Agents and Multiagent Systems. 


\section{Appendix A: Detail on CapaCity Differences CaUsed by MISFORECASTING}

Figure A-1 shows the differences in capacity built under various misforecasts compared to the capacity built under a correct forecast, for three different DPV energy penetration scenarios. The results for the $5 \%$ scenario were shown previously in Figure 5, but higher and lower DPV scenarios have been added for comparison. The strong coupling between DPV forecast error and UPV capacity additions can be observed here through year 10, although the coupling is somewhat weaker by the end of the 15th year. Relatively strong path dependencies are at play here, where changes in installed capacity in year 10 can lead to divergent system needs in year 15. These effects compound year after year, leading to less-thanstraightforward results by the end of the simulation.

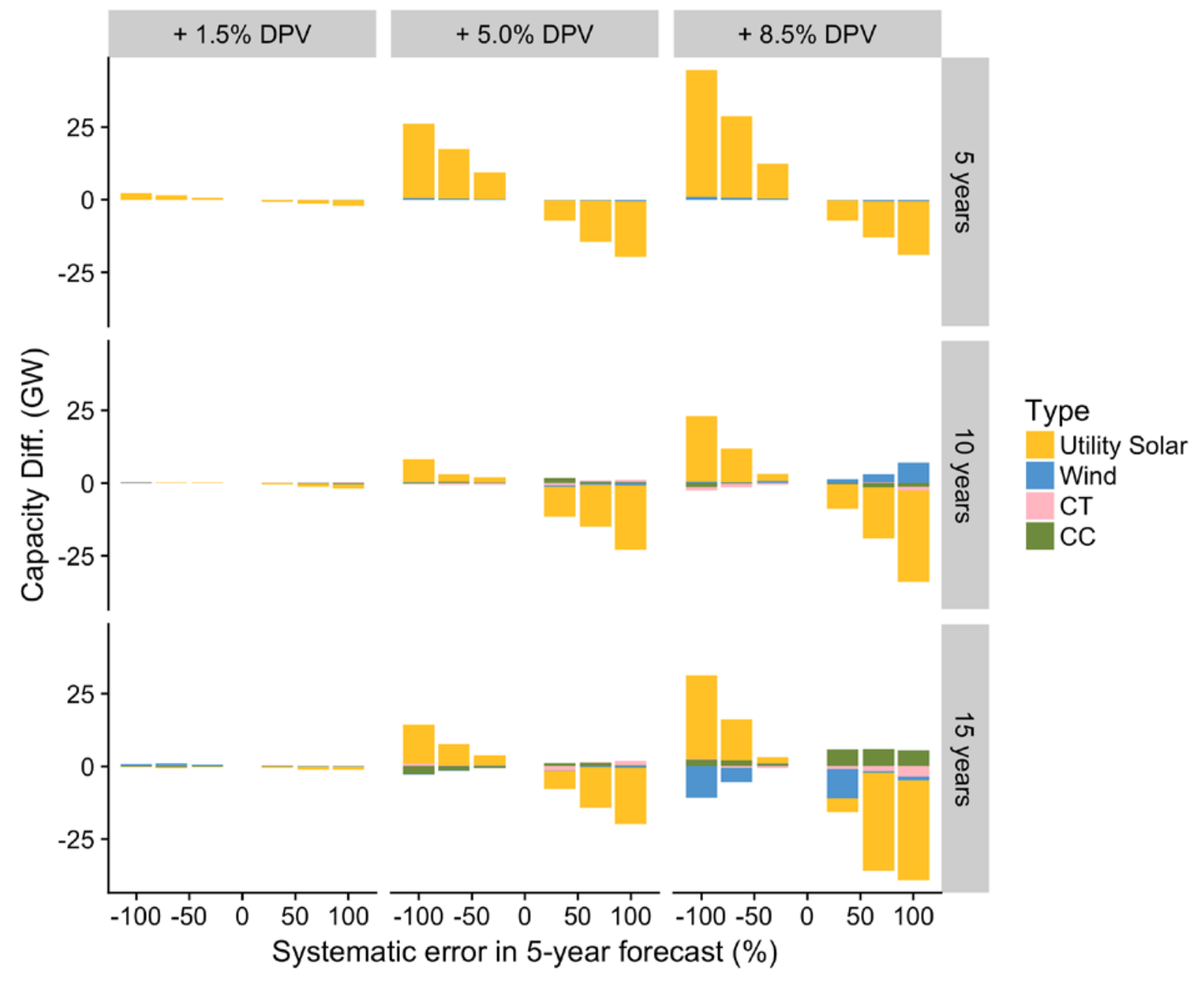

Figure A-1. Influence of forecast error on capacity additions for three DPV penetration scenarios, relative to the capacity added when forecasting is perfect 


\section{Appendix B: Detalled Methodology for Estimating Value OF IMPROVED FORECASTING}

This appendix contains a step-by-step method for estimating the value of improved DPV forecasting. This method was mentioned in Section 3.3 but is given in more detail here.

1. Estimate the range of possible increases in DPV energy penetrations that could occur in the region of interest over the next 15 years, assigning a probability to discrete values within that range.

2. Select the increase in DPV energy penetration that would most likely be used for resource planning purposes, given current understanding.

3. Use the following equation to calculate the implied forecast error for each of the other discrete DPV penetration increases from Step 1 (i.e., assuming each of those penetration increases is what ultimately occurs), if the value in Step 2 is planned for. ${ }^{25}$

$$
\text { systematic forecast error }=\frac{D P V \text { increase planned for }}{D P V \text { increase that occurs }}-1
$$

4. Look up the $\$ / T W h$ value for each of the DPV energy penetration increase and forecast error combinations, multiplying by the size of the system under consideration to get the cost of forecast error for each possibility across the range in Step 1. Use Figure 9 or the tables in Appendix $C$ to look up these values.

5. Calculate the average of the dollar values from Step 4, weighting each by its likelihood of occurring as estimated in Step 1-this is the expected cost of forecast error under current forecasting capabilities.

6. Look up the $\$ / T W h$ value for each of the same increases in DPV penetration, but with a reduced value of systematic error. Multiply them by the size of the system to get the cost of each point in dollars.

7. Calculate the probability-weighted average of these new values - this is the expected cost under improved forecasting capabilities.

8. Subtract the expected cost under improved forecasting capabilities (Step 7) from the expected cost under current forecasting capabilities (Step 5) - this is the final estimate of the total present value of the improved forecasting accuracy.

Next we give an example of these steps for a hypothetical utility. In Step 1, the utility estimates that the increase in DPV energy penetration over the next 15 years could range from $2 \%$ to $7.5 \%$. It assigns a $25 \%$ probability to a $2 \%$ increase occurring, a $50 \%$ probability to $3.5 \%$ occurring, and a $25 \%$ probability to $7.5 \%$ occurring. ${ }^{26}$ It considers a 3.5\% DPV penetration increase to be the most likely and assumes that value will be used in the first 5-year period of the resource planning process (Step 2). Using the equation

\footnotetext{
${ }^{25}$ Our method assumes the utility will systematically misforecast DPV with the same severity in each 5-year planning period, even as it updates its plans. Therefore, using year 15 "planned" and "actual" DPV penetrations is simply a way to calculate the severity of systematic forecast error, even though the "planned" penetration will be periodically updated prior to year 15 . Because the underlying models follow this assumption, our results cannot be directly used to estimate costs for situations without systematic error, although the values derived from consideration of systematic error can be useful guides in roughly estimating the cost of forecast error under different types of misforecasting patterns.

${ }^{26}$ In practice we recommend a higher number of discrete points being selected, including at least several lowprobability events on the extreme edges. Here we only show three discrete points for the sake of simplicity.
} 
in Step 3, it calculates that an actual DPV penetration corresponding to its low guess would result in a $75 \%$ overforecast, and an actual penetration corresponding to its high guess would result in a $-53 \%$ underforecast.

These points are illustrated by Line A in Figure B-1. Using the tables in Appendix C per Step 4, we can interpolate the values as \$2.4 million/TWh (higher than expected adoption), \$0/TWh (expected adoption), and $\$ 0.36$ million/TWh (lower than expected adoption). If the utility sold $10 \mathrm{TWh} /$ year of electricity for end-use consumption, those values would equate to costs of \$24 million, \$0, and \$3.6 million from forecast error in 2017 dollars. These are the total additional costs the utility is estimated to incur from misforecasting in each of the discrete situations under consideration, assuming it updates its plans every 5 years but still systematically misforecasts future DPV with the same severity.

Per Step 5, the utility calculates the weighted average of the values derived in Step 4: $(0.25 \times \$ 24$ million $)$ $+(0.5 \times \$ 0)+(0.25 \times \$ 3.6$ million $)=\$ 6.9$ million. Thus $\$ 6.9$ million is the expected total cost of misforecasting error for the range of DPV penetrations that the utility considered possible with its current forecasting capabilities.

In Step 6, the utility selects target systematic error values of $\pm 25 \%$ (indicated by Line B in Figure B-1), which it hopes to achieve with improved forecasting capabilities. Note that the costs corresponding to these new points are determined by moving the systematic error values inward, but without changing the range of possible DPV penetrations or their accompanying probabilities. At this stage, the utility has no better information about what DPV penetration is more likely to occur-only that, whatever the actual penetration, the utility would be able to forecast that penetration more accurately with better forecasting capabilities. Thus the planned/actual DPV penetrations and forecast error are not coupled mathematically in this step as they are in Step 3; the new "DPV planned for" would be established only after the hypothetical investment in better forecasting capabilities is made. ${ }^{27}$

By calculating the weighted average cost of these new points, the utility estimates that the expected cost of forecast error under improved forecasting is $(0.25 \times \$ 10$ million $)+(0.5 \times \$ 0)+(0.25 \times \$ 1.7$ million $)=$ \$2.9 million (Step 7).

As given in Step 8, the utility can then estimate the total present value of its assumed forecasting capability improvement: $\$ 6.9$ million $-\$ 2.9$ million $=\$ 4.0$ million in 2017 dollars. If the utility believes that the total present-value cost of the tools, training, or personnel required to achieve that degree of forecasting accuracy is significantly less than the expected cost savings, then it may be financially prudent to make the investment.

\footnotetext{
${ }^{27}$ To give a numerical example, assume that-using improved forecasting capability — the utility plans for an increase of 5.625\% DPV penetration (instead of 3.5\%, as it would have planned for under its old forecasting capability), and the actual DPV penetration increases by the high estimate of $7.5 \%$ in year 15 . This equates to a forecast error of $-25 \%$, which is better than the $-53 \%$ that would have occurred under the old forecasting capability.
} 


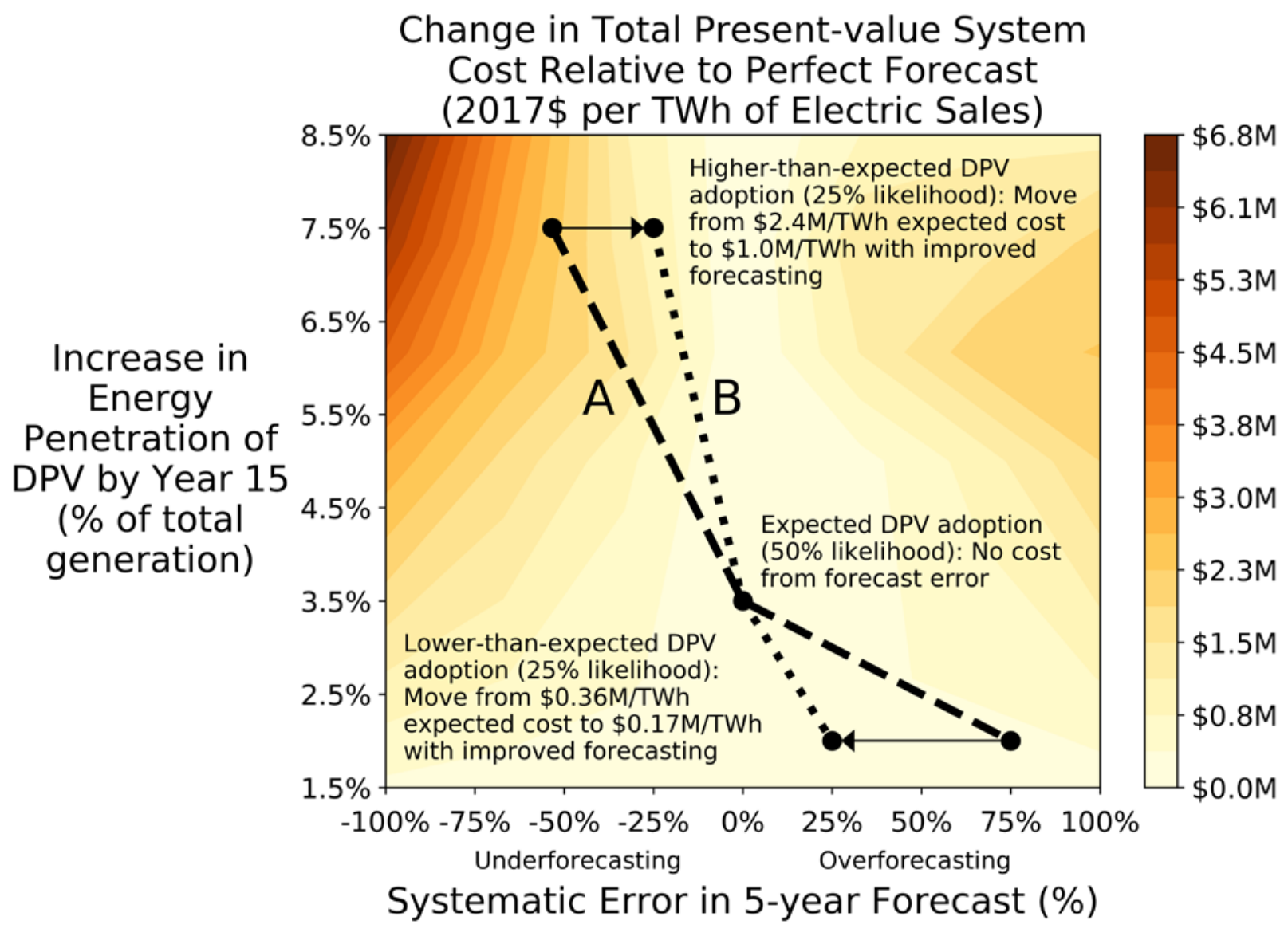

Figure B-1. Illustration of cost savings from improving DPV forecasts 


\section{APPENDIX C: LOOKUP TABLES}

Table C-1 and Table C-2 are lookup tables that give the total present-value costs of forecast error. These are the same data presented in Figure 9, likewise presented in millions of 2017\$ per TWh of retail electricity sales that the misforecasting entity made in the most recent year. For example, if a utility experiences an 8.5\% increase in DPV energy penetration over a 15-year period, and systematically underforecasted that DPV growth by $-100 \%$, its costs would be $\$ 6.82$ million/TWh higher than what its costs would have been under perfect forecasting. If the utility sold $10 \mathrm{TWh}$ of electricity in the most recent year, that would be a cost of $\$ 68.2$ million. These tables can be used with the method detailed in Appendix B.

Table C-1. Present-value Costs of Underforecasting (2017\$ million per TWh of electric sales)

\begin{tabular}{|c|c|c|c|c|c|c|c|c|c|c|c|c|}
\hline & \multicolumn{11}{|c|}{ Systematic Error in 5-year Forecast (\%) } \\
\hline & & $-100 \%$ & $-90 \%$ & $-80 \%$ & $-70 \%$ & $-60 \%$ & $-50 \%$ & $-40 \%$ & $-30 \%$ & $-20 \%$ & $-10 \%$ & $0 \%$ \\
\hline \multirow{29}{*}{$\begin{array}{c}\text { Increase in } \\
\text { Energy } \\
\text { Penetration } \\
\text { of DPV over } \\
15 \text { years (\% } \\
\text { of total } \\
\text { generation) }\end{array}$} & $8.50 \%$ & 6.82 & 5.85 & 4.87 & 3.89 & 3.10 & 2.39 & 1.67 & 1.06 & 0.71 & 0.35 & 0.00 \\
\hline & $8.25 \%$ & 6.59 & 5.75 & 4.77 & 3.80 & 3.00 & 2.29 & 1.58 & 1.08 & 0.71 & 0.35 & 0.00 \\
\hline & $8.00 \%$ & 6.35 & 5.57 & 4.67 & 3.70 & 2.90 & 2.19 & 1.61 & 1.11 & 0.71 & 0.35 & 0.00 \\
\hline & $7.75 \%$ & 6.12 & 5.33 & 4.55 & 3.60 & 2.81 & 2.18 & 1.64 & 1.15 & 0.75 & 0.35 & 0.00 \\
\hline & $7.50 \%$ & 5.88 & 5.10 & 4.32 & 3.50 & 2.75 & 2.21 & 1.67 & 1.18 & 0.78 & 0.38 & 0.00 \\
\hline & $7.25 \%$ & 5.64 & 4.86 & 4.07 & 3.29 & 2.79 & 2.25 & 1.71 & 1.22 & 0.82 & 0.42 & 0.00 \\
\hline & $7.00 \%$ & 5.38 & 4.60 & 3.82 & 3.17 & 2.78 & 2.30 & 1.77 & 1.27 & 0.87 & 0.47 & 0.00 \\
\hline & $6.75 \%$ & 5.13 & 4.34 & 3.64 & 3.06 & 2.67 & 2.36 & 1.82 & 1.33 & 0.93 & 0.48 & 0.00 \\
\hline & $6.50 \%$ & 4.87 & 4.10 & 3.53 & 2.96 & 2.57 & 2.25 & 1.88 & 1.38 & 0.95 & 0.48 & 0.00 \\
\hline & $6.25 \%$ & 4.61 & 3.99 & 3.42 & 2.85 & 2.46 & 2.14 & 1.83 & 1.43 & 0.95 & 0.48 & 0.00 \\
\hline & $6.00 \%$ & 4.30 & 3.73 & 3.16 & 2.62 & 2.30 & 1.99 & 1.67 & 1.39 & 0.95 & 0.48 & 0.00 \\
\hline & $5.75 \%$ & 3.96 & 3.39 & 2.82 & 2.44 & 2.12 & 1.80 & 1.51 & 1.24 & 0.95 & 0.48 & 0.00 \\
\hline & $5.50 \%$ & 3.62 & 3.05 & 2.60 & 2.26 & 1.93 & 1.63 & 1.35 & 1.08 & 0.83 & 0.48 & 0.00 \\
\hline & $5.25 \%$ & 3.28 & 2.77 & 2.42 & 2.07 & 1.75 & 1.47 & 1.20 & 0.93 & 0.67 & 0.41 & 0.00 \\
\hline & $5.00 \%$ & 2.93 & 2.59 & 2.24 & 1.89 & 1.59 & 1.32 & 1.04 & 0.77 & 0.51 & 0.26 & 0.00 \\
\hline & $4.75 \%$ & 2.74 & 2.48 & 2.13 & 1.78 & 1.55 & 1.27 & 1.00 & 0.73 & 0.47 & 0.21 & 0.00 \\
\hline & $4.50 \%$ & 2.54 & 2.37 & 2.02 & 1.67 & 1.50 & 1.23 & 0.95 & 0.68 & 0.43 & 0.17 & 0.00 \\
\hline & $4.25 \%$ & 2.34 & 2.24 & 1.91 & 1.56 & 1.39 & 1.19 & 0.91 & 0.64 & 0.39 & 0.14 & 0.00 \\
\hline & $4.00 \%$ & 2.14 & 2.04 & 1.80 & 1.45 & 1.28 & 1.14 & 0.87 & 0.60 & 0.34 & 0.14 & 0.00 \\
\hline & $3.75 \%$ & 1.94 & 1.84 & 1.69 & 1.34 & 1.17 & 1.08 & 0.83 & 0.56 & 0.30 & 0.14 & 0.00 \\
\hline & $3.50 \%$ & 1.74 & 1.65 & 1.55 & 1.23 & 1.06 & 0.97 & 0.78 & 0.51 & 0.27 & 0.14 & 0.00 \\
\hline & $3.25 \%$ & 1.54 & 1.45 & 1.35 & 1.12 & 0.95 & 0.86 & 0.74 & 0.47 & 0.27 & 0.14 & 0.00 \\
\hline & $3.00 \%$ & 1.34 & 1.25 & 1.15 & 1.01 & 0.84 & 0.75 & 0.66 & 0.43 & 0.27 & 0.14 & 0.00 \\
\hline & $2.75 \%$ & 1.14 & 1.05 & 0.95 & 0.86 & 0.73 & 0.64 & 0.55 & 0.41 & 0.27 & 0.14 & 0.00 \\
\hline & $2.50 \%$ & 0.97 & 0.87 & 0.77 & 0.69 & 0.61 & 0.52 & 0.43 & 0.39 & 0.27 & 0.14 & 0.00 \\
\hline & $2.25 \%$ & 0.80 & 0.70 & 0.61 & 0.57 & 0.49 & 0.40 & 0.34 & 0.32 & 0.27 & 0.14 & 0.00 \\
\hline & $2.00 \%$ & 0.63 & 0.53 & 0.47 & 0.44 & 0.37 & 0.29 & 0.27 & 0.25 & 0.21 & 0.14 & 0.00 \\
\hline & $1.75 \%$ & 0.46 & 0.38 & 0.35 & 0.32 & 0.24 & 0.22 & 0.20 & 0.17 & 0.14 & 0.11 & 0.00 \\
\hline & $1.50 \%$ & 0.29 & 0.26 & 0.23 & 0.19 & 0.17 & 0.15 & 0.13 & 0.10 & 0.07 & 0.03 & 0.00 \\
\hline
\end{tabular}


Table C-2. Present-value Costs of Overforecasting (2017\$ million per TWh of electric sales)

\begin{tabular}{|c|c|c|c|c|c|c|c|c|c|c|c|c|}
\hline & \multicolumn{11}{|c|}{ Systematic Error in 5-year Forecast (\%) } \\
\hline & & $0 \%$ & $10 \%$ & $20 \%$ & $30 \%$ & $40 \%$ & $50 \%$ & $60 \%$ & $70 \%$ & $80 \%$ & $90 \%$ & $100 \%$ \\
\hline \multirow{29}{*}{$\begin{array}{c}\text { Increase in } \\
\text { Energy } \\
\text { Penetration } \\
\text { of DPV over } \\
15 \text { years (\% } \\
\text { of total } \\
\text { generation) }\end{array}$} & $8.50 \%$ & 0.00 & 0.23 & 0.46 & 0.69 & 0.82 & 0.92 & 1.01 & 1.06 & 1.04 & 1.01 & 0.98 \\
\hline & $8.25 \%$ & 0.00 & 0.37 & 0.61 & 0.84 & 0.97 & 1.06 & 1.15 & 1.19 & 1.26 & 1.24 & 1.21 \\
\hline & $8.00 \%$ & 0.00 & 0.43 & 0.75 & 0.98 & 1.11 & 1.20 & 1.20 & 1.25 & 1.46 & 1.46 & 1.44 \\
\hline & $7.75 \%$ & 0.00 & 0.43 & 0.87 & 1.12 & 1.26 & 1.29 & 1.26 & 1.31 & 1.52 & 1.69 & 1.67 \\
\hline & $7.50 \%$ & 0.00 & 0.43 & 0.87 & 1.27 & 1.38 & 1.35 & 1.32 & 1.36 & 1.58 & 1.79 & 1.89 \\
\hline & $7.25 \%$ & 0.00 & 0.41 & 0.85 & 1.28 & 1.39 & 1.37 & 1.34 & 1.42 & 1.63 & 1.85 & 2.06 \\
\hline & $7.00 \%$ & 0.00 & 0.35 & 0.79 & 1.22 & 1.33 & 1.31 & 1.36 & 1.58 & 1.69 & 1.90 & 2.12 \\
\hline & $6.75 \%$ & 0.00 & 0.35 & 0.73 & 1.16 & 1.27 & 1.25 & 1.54 & 1.76 & 1.80 & 1.96 & 2.17 \\
\hline & $6.50 \%$ & 0.00 & 0.35 & 0.70 & 1.10 & 1.21 & 1.42 & 1.72 & 1.93 & 1.98 & 2.02 & 2.22 \\
\hline & $6.25 \%$ & 0.00 & 0.35 & 0.70 & 1.05 & 1.30 & 1.60 & 1.89 & 2.11 & 2.15 & 2.19 & 2.28 \\
\hline & $6.00 \%$ & 0.00 & 0.35 & 0.70 & 1.00 & 1.19 & 1.48 & 1.78 & 1.99 & 2.04 & 2.08 & 2.24 \\
\hline & $5.75 \%$ & 0.00 & 0.35 & 0.70 & 0.81 & 0.97 & 1.22 & 1.52 & 1.74 & 1.78 & 1.86 & 2.15 \\
\hline & $5.50 \%$ & 0.00 & 0.35 & 0.54 & 0.61 & 0.78 & 0.99 & 1.26 & 1.48 & 1.52 & 1.78 & 2.07 \\
\hline & $5.25 \%$ & 0.00 & 0.27 & 0.34 & 0.42 & 0.58 & 0.79 & 1.00 & 1.22 & 1.41 & 1.69 & 1.98 \\
\hline & $5.00 \%$ & 0.00 & 0.07 & 0.15 & 0.22 & 0.39 & 0.59 & 0.80 & 1.03 & 1.32 & 1.61 & 1.90 \\
\hline & $4.75 \%$ & 0.00 & 0.08 & 0.16 & 0.23 & 0.34 & 0.54 & 0.75 & 0.92 & 1.20 & 1.49 & 1.78 \\
\hline & $4.50 \%$ & 0.00 & 0.09 & 0.16 & 0.24 & 0.29 & 0.49 & 0.70 & 0.87 & 1.08 & 1.37 & 1.65 \\
\hline & $4.25 \%$ & 0.00 & 0.10 & 0.17 & 0.25 & 0.30 & 0.44 & 0.64 & 0.82 & 0.96 & 1.25 & 1.53 \\
\hline & $4.00 \%$ & 0.00 & 0.10 & 0.18 & 0.25 & 0.30 & 0.38 & 0.59 & 0.76 & 0.86 & 1.12 & 1.41 \\
\hline & $3.75 \%$ & 0.00 & 0.10 & 0.19 & 0.26 & 0.31 & 0.35 & 0.54 & 0.71 & 0.81 & 1.00 & 1.29 \\
\hline & $3.50 \%$ & 0.00 & 0.10 & 0.20 & 0.27 & 0.32 & 0.36 & 0.49 & 0.66 & 0.75 & 0.88 & 1.17 \\
\hline & $3.25 \%$ & 0.00 & 0.10 & 0.20 & 0.28 & 0.33 & 0.37 & 0.43 & 0.61 & 0.70 & 0.80 & 1.05 \\
\hline & $3.00 \%$ & 0.00 & 0.10 & 0.20 & 0.29 & 0.34 & 0.38 & 0.42 & 0.55 & 0.65 & 0.74 & 0.93 \\
\hline & $2.75 \%$ & 0.00 & 0.10 & 0.20 & 0.29 & 0.35 & 0.39 & 0.43 & 0.50 & 0.60 & 0.69 & 0.81 \\
\hline & $2.50 \%$ & 0.00 & 0.10 & 0.20 & 0.28 & 0.32 & 0.36 & 0.40 & 0.44 & 0.53 & 0.63 & 0.68 \\
\hline & $2.25 \%$ & 0.00 & 0.10 & 0.20 & 0.24 & 0.27 & 0.31 & 0.34 & 0.37 & 0.47 & 0.55 & 0.56 \\
\hline & $2.00 \%$ & 0.00 & 0.10 & 0.16 & 0.19 & 0.23 & 0.26 & 0.27 & 0.31 & 0.40 & 0.42 & 0.44 \\
\hline & $1.75 \%$ & 0.00 & 0.08 & 0.11 & 0.14 & 0.18 & 0.19 & 0.21 & 0.24 & 0.29 & 0.30 & 0.31 \\
\hline & $1.50 \%$ & 0.00 & 0.03 & 0.06 & 0.10 & 0.11 & 0.13 & 0.14 & 0.15 & 0.16 & 0.18 & 0.19 \\
\hline
\end{tabular}




\section{APPENDIX D: BREAKDOWN OF SENSITIVITY SCENARIO COSTS}

Figure 12 in the body of the report gave the total present-value cost of each sensitivity scenario across a range of misforecasts and DPV increases. Figure D-1 separates these total costs into capital and operating costs.

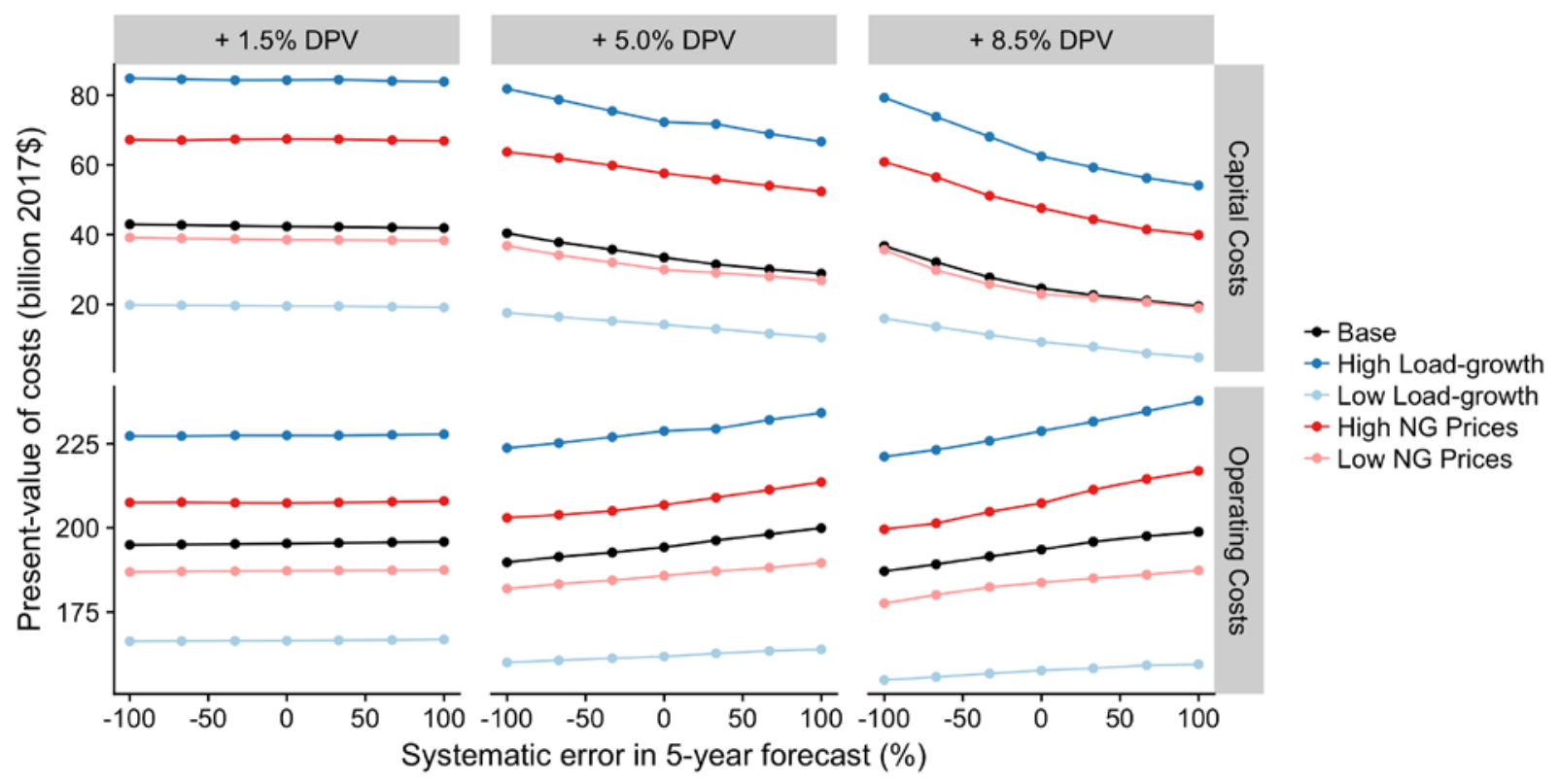

Figure D-1. Capital and operating costs for sensitivity scenarios 
National Renewable Energy Laboratory

15013 Denver West Parkway

Golden, CO 80401

303-275-3000 • www.nrel.gov
Lawrence Berkeley National Laboratory

1 Cyclotron Road

Berkeley, CA 94720

510-486-4000 • www.lbl.gov
NREL/TP-6A20-71042 • May 2018

Printed on paper that contains recycled content. 